\title{
A CARTILAGE GROWTH MIXTURE MODEL FOR INFINITESIMAL STRAINS: SOLUTIONS OF BOUNDARY-VALUE PROBLEMS RELATED TO IN VITRO GROWTH EXPERIMENTS
}

\author{
Stephen M. Klisch ${ }^{1}$, Robert L. Sah ${ }^{2}$, and Anne Hoger ${ }^{3}$ \\ ${ }^{1}$ Department of Mechanical Engineering, California Polytechnic State University, San Luis \\ Obispo, CA \\ ${ }^{2}$ Department of Bioengineering, University of California at San Diego, La Jolla, CA \\ ${ }^{3}$ Department of Mechanical and Aerospace Engineering, University of California at San Diego, \\ La Jolla, CA
}

\section{PUBLISHED CITATION}

Klisch SM, Sah RL, Hoger A. A cartilage growth mixture model for infinitesimal strains: solutions of boundary-value problems related to in vitro growth experiments. Biomechanics and Modeling in Mechanobiology 3: 209-223, 2005

Address all correspondence to:

Stephen M. Klisch, Ph.D.

Associate Professor

Mechanical Engineering Department

California Polytechnic State University

San Luis Obispo, CA 93407

(805) 756-1308; FAX (805) 756-1137

sklisch@calpoly.edu 


\section{ABSTRACT}

A cartilage growth mixture (CGM) model is linearized for infinitesimal elastic and growth strains. Parametric studies for equilibrium and non-equilibrium boundaryvalue problems representing the in vitro growth of cylindrical cartilage constructs are

5 solved. The results show that the CGM model is capable of describing the main biomechanical features of cartilage growth. The solutions to the equilibrium problems reveal that tissue composition, constituent pre-stresses, and geometry depend on collagen remodeling activity, growth symmetry, and differential growth. Also, nonhomogeneous growth leads to nonhomogeneous tissue composition and constituent pre-stresses. The

10 solution to the non-equilibrium problem reveals that the tissue is nearly in equilibrium at all time points. The results suggest that the CGM model may be used in the design of tissue engineered cartilage constructs for the repair of cartilage defects; for example, to predict how dynamic mechanical loading affects the development of nonuniform properties during in vitro growth. Furthermore, the results lay the foundation for future

15 analyses with nonlinear models that are needed to develop realistic models of cartilage growth.

\section{INTRODUCTION}

Articular cartilage functions as a low friction, wear-resistant, load-bearing material that facilitates joint motion (Maroudas and Venn 1977; Mow and Ratcliffe

20 1997). The two primary molecular components of the solid matrix, proteoglycan and collagen, appear to have distinct mechanical roles. The proteoglycans provide the tissue with a fixed negative charge that increases the tissue's propensity to swell and to resist 
compressive loading (Basser et al. 1998; Lai et al. 1991). The crosslinked collagen network resists the swelling tendency of the proteoglycan, and provides the tissue with tensile and shear stiffness and strength (Mow and Ratcliffe 1997; Venn and Maroudas 1977; Woo et al. 1976). The mechanical properties of articular cartilage depend on both proteoglycan and collagen contents (Maroudas et al. 1968; Mow and Ratcliffe 1997; Sah et al. 1996) and vary with depth from the articular surface (Chen et al. 2001a; Guilak et al. 1995; Schinagl et al. 1997; Setton et al. 1993). These spatial variations are likely related to the heterogeneity of tissue composition, as distinct zones of articular cartilage (i.e., superficial, middle, and deep) have been identified that vary in composition and 10 structure (Buckwalter and Mankin 1998).

The cartilage extracellular matrix is synthesized, maintained, and degraded by chondrocytes. A key feature of cartilage growth is that cell and matrix metabolism can be regulated by mechanical stimuli. In vitro experiments with cartilage explants have quantified the metabolic response to mechanical stimuli such as hydrostatic pressure,

15 dynamic compressive stress, and fluid shear (Guilak et al. 1997). Towards the aim of developing quantitative models of cartilage growth, in recent years we have extended continuum theories of growth (Rodriguez et al. 1994; Skalak et al. 1982; Skalak et al. 1996; Skalak et al. 1997) to describe the growth of compressible elastic, thermoelastic, and multiphasic materials (Klisch et al. 2000; Klisch et al. 2001; Klisch and Hoger 2003).

20 Since both the pre-stresses ${ }^{1}$ and the mechanical properties of the proteoglycan and collagen constituents are crucial to the function of the tissue, we have proposed a cartilage growth mixture (CGM) model that allows for the specification of multiple

\footnotetext{
${ }^{1}$ We define pre-stress as the constituent stress in a local configuration for which the solid matrix stress is zero.
} 
constituents that may grow and remodel in distinct ways (Klisch et al. 2000; Klisch et al. 2003; Klisch and Hoger 2003). Related theories of growth have been presented recently by other authors for thermoelastic materials (Epstein and Maugin 2000; Lubarda and Hoger 2002; Menzel 2005) and mixtures (Garikipati et al. 2004; Humphrey and

5 Rajagopal 2002; Quiligotti 2002). Despite all of this work, realistic models of cartilage growth have not yet been developed, as many model parameters have not been experimentally characterized.

Since the CGM model has only been recently proposed, few boundary-value problems have been described and solved. In continuum mechanics, the governing 10 equations are numerous, nonlinear, and coupled; typically, the solution of boundary-value problems are crucial for developing an intuitive understanding of a new theory. In this paper, we solve boundary-value problems in order to better understand how the CGM model works and to gain insight into how the model may be used with tissue engineering experiments. Due to the inherent difficulties in using finite deformation theories, here we

15 develop a CGM model for infinitesimal strains and seek analytical solutions to specific boundary-value problems. Analytical solutions are useful as they may highlight which parameters most affect the solutions and, consequently, identify the areas in which experimentation and theory should be focused in an attempt to develop validated models.

The specific boundary-value problems were chosen to investigate the relative 20 effects of collagen remodeling activity, growth symmetry, growth heterogeneity, and differential growth on tissue structure and function for current in vitro experimental protocols. These experimental protocols include growth of either tissue engineered constructs or native tissue explants under free swelling, static, or dynamic loading 
conditions in both unconfined (Buschmann et al. 1999; Kisiday et al. 2004; Mauck et al. 2000; Sah et al. 1989; Thibault et al. 2002; Williamson et al. 2003) and radially confined (Davisson et al. 2002a; Davisson et al. 2002b; Dunkelman et al. 1995; Pazzano et al. 2000; Schreiber et al. 1999) configurations. In this paper, collagen remodeling activity is

5 defined as a change in collagen material constants to reflect an enhancement in collagen integrity via increased crosslink density, growth symmetry is defined as the orientation of mass deposition, growth heterogeneity is defined through spatially-varying mass deposition, and differential growth is defined by the relative amounts of proteoglycan and collagen mass deposition.

10 The objectives of this study were: (1) to linearize a CGM model for infinitesimal strains and (2) to use this model to solve boundary-value problems related to in vitro growth of cartilage constructs. Currently available experimental data are not sufficient to determine all of the model's parameters and constitutive equations, so the analyses presented here include a number of simplifying assumptions including infinitesimal

15 deformations, isotropic material symmetry, and homogeneous material properties. $^{2}$ Consequently, the results are intended to serve as a foundation for developing solutions to boundary-value problems related to in vitro growth experiments using future refinements of the model.

\section{METHODS}

20 Cartilage growth model for finite deformations

\footnotetext{
${ }^{2}$ See the discussion section for proposed future studies aimed at addressing these limitations.
} 
The governing equations of the CGM model for finite deformations are obtained from the general growth mixture theory for an arbitrary number of constituents presented in (Klisch et al. 2000; Klisch and Hoger 2003) with the following assumptions:

(1) The mixture is composed of four constituents: a growing proteoglycan elastic

5 material, a growing collagen elastic network, an inviscid fluid representing water and dissolved solutes, and "others" representing the non-collageneous proteins. The "others" may grow through mass increase via cellular metabolism or matrix degradation or through mass decrease via conversion into functional proteoglycan or collagen molecules.

10 (2) The proteoglycans, collagens, and "others" are bound to the extracellular matrix and, consequently, are constrained to experience the same overall motion. This is a limitation as $20-40 \%$ of the proteoglycans are soluble and mobile in the tissue matrix (Pottenger et al. 1985; Sajdera and Hascall 1969); however, the general theory (Klisch et al. 2000; Klisch and Hoger 2003) allows for the specification of mobile constituents.

15 (3) The mixture is constrained to be intrinsically incompressible. This constraint (Frank and Grodzinsky 1987; Mills 1966; Mow et al. 1980) has been demonstrated experimentally for physiologic load levels (Bachrach et al. 1998).

(4) The proteoglycan stress depends on the proteoglycan, collagen, and water densities. In particular, we use a two-compartmental model (Basser et al. 1998) in which the 20 proteoglycan stress is calculated from an effective fixed charge density and depends on proteoglycan, collagen, and water contents. 
(5) The collagen stress depends only on the elastic deformation of the collagen constituent. This assumption is made as there is insufficient data to quantify how other matrix molecules affect the mechanical properties of the collagen network.

(6) The determinate fluid stress and the determinate stress in the "others" are both zero.

5 Assuming the determinate fluid stress to be zero is equivalent to assuming a constant fluid free energy function (Klisch and Lotz 2000). We assume that the others do not contribute directly to the mechanical properties of the solid matrix.

The governing equations for this CGM model valid for finite deformations are obtained from the general theory of (Klisch et al. 2000; Klisch and Hoger 2003) and are

10 presented in the appendix.

Cartilage growth model for infinitesimal deformations

We assume a homogeneous reference configuration with uniform constituent densities and zero pore pressure. A homogeneous reference configuration may be reasonable for constructs grown from isolated chondrocytes or for explants harvested

15 from immature bovine joints, which are nearly uniform in tissue composition (Buschmann et al. 1999). The governing equations presented in the appendix are linearized by assuming that the magnitudes of the solid matrix displacement vector, fluid density change, pore pressure, mass growth functions, and remodeling parameter to be order epsilon, and retaining only terms that are first order in epsilon (i.e., discarding all

20 higher order terms) in the governing equations. Many of the intermediate steps are not shown as the linearization procedure is essentially the same as that outlined in (Green and Naghdi 1970) for solid-fluid mixtures.

\section{$\underline{\text { Kinematics }}$}


The solid matrix infinitesimal strain tensor $\mathbf{e}^{\mathrm{s}}$ may be expressed as

$$
\mathbf{e}^{\mathrm{s}}=\frac{1}{2}\left\{\left(\mathbf{F}^{\mathrm{s}}-\mathbf{I}\right)+\left(\mathbf{F}^{\mathrm{s}}-\mathbf{I}\right)^{\mathrm{T}}\right\}
$$

where $\mathbf{F}^{\mathrm{S}}$ is the solid matrix deformation gradient tensor, $\mathbf{I}$ is the identity tensor, the quantity $\left(\mathbf{F}^{\mathrm{s}}-\mathbf{I}\right)$ is solid matrix displacement gradient tensor $\mathbf{H}^{\mathrm{s}}=\partial \mathbf{u}^{\mathrm{s}} / \partial \mathbf{X}$, and $\mathrm{T}$ is the

5 transpose operator. ${ }^{3}$ For non-compatible growth, there do not exist single-valued displacement fields corresponding to elastic and growth deformations (Skalak et al. 1996). Consequently, we define infinitesimal elastic $\left(\mathbf{e}_{\mathrm{e}}^{\alpha}\right)$ and growth $\left(\mathbf{e}_{\mathrm{g}}^{\alpha}\right)$ strain tensors for the growing solid matrix constituents as

$$
\mathbf{e}_{\mathrm{e}}^{\alpha}=\frac{1}{2}\left\{\left(\mathbf{M}_{\mathrm{e}}^{\alpha}-\mathbf{I}\right)+\left(\mathbf{M}_{\mathrm{e}}^{\alpha}-\mathbf{I}\right)^{\mathrm{T}}\right\}, \quad \mathbf{e}_{\mathrm{g}}^{\alpha}=\frac{1}{2}\left\{\left(\mathbf{M}_{\mathrm{g}}^{\alpha}-\mathbf{I}\right)+\left(\mathbf{M}_{\mathrm{g}}^{\alpha}-\mathbf{I}\right)^{\mathrm{T}}\right\}
$$

10 where $\mathbf{M}_{\mathrm{e}}^{\alpha}$ is the finite elastic accommodation tensor and $\mathbf{M}_{\mathrm{g}}^{\alpha}$ is the finite growth tensor. ${ }^{4}$ Linearization of the multiplicative decompositions of the deformation gradient tensors (A1) leads to

$$
\mathbf{e}^{\alpha}=\mathbf{e}_{\mathrm{e}}^{\alpha}+\mathbf{e}_{\mathrm{g}}^{\alpha}
$$

whereas linearization of the constraint (A4) leads to

$$
\mathbf{e}^{\mathrm{s}}=\mathbf{e}^{\alpha}\left(\Rightarrow \mathbf{e}_{\mathrm{e}}^{\mathrm{p}}+\mathbf{e}_{\mathrm{g}}^{\mathrm{p}}=\mathbf{e}_{\mathrm{e}}^{\mathrm{c}}+\mathbf{e}_{\mathrm{g}}^{\mathrm{c}}=\mathbf{e}_{\mathrm{e}}^{\mathrm{oth}}+\mathbf{e}_{\mathrm{g}}^{\mathrm{oth}}\right)
$$

This tensor description of growth allows for anisotropic growth, which may be necessary to include for modeling cartilage as experimental results (Buschmann et al. 1996) suggest that proteoglycans may be preferably deposited in a plane normal to the direction of

\footnotetext{
${ }^{3}$ If $\mathbf{X}$ and $\mathbf{x}$ denote material and spatial coordinates, respectively, then $\mathbf{H}^{\mathrm{s}}=\partial \mathbf{u}^{\mathrm{s}} / \partial \mathbf{X} \sim \partial \mathbf{u} / \partial \mathbf{x}$ in the linear theory.

${ }^{4}$ The superscript $\alpha$ will be used to designate the proteoglycans (p), collagens (c), and others (oth).
} 
applied compressive loading. ${ }^{5}$ Equations (A2) (defining the diffusive velocity a) and (A3) (constraining the solid matrix constituent displacement and velocity vectors to equal $\mathbf{u}^{\mathrm{s}}$ and $\mathbf{v}^{\mathrm{s}}$, respectively) hold in the linearization. Linearization of other kinematical relations leads to

$$
\begin{aligned}
& \mathbf{v}^{\mathrm{s}}=\frac{\partial \mathbf{u}^{\mathrm{s}}}{\partial \mathrm{t}}, \quad \operatorname{det} \mathbf{F}^{\alpha}=1+\operatorname{tre}^{\alpha}, \quad \operatorname{det} \mathbf{M}_{\mathrm{e}}^{\alpha}=1+\operatorname{tr} \mathbf{e}_{\mathrm{e}}^{\alpha}, \\
& \operatorname{det}_{\mathrm{g}}^{\alpha}=1+\operatorname{tre}_{\mathrm{g}}^{\alpha}, \quad\left(\operatorname{det} \mathbf{M}_{\mathrm{e}}^{\alpha}\right)^{-1}=1-\operatorname{tre}_{\mathrm{e}}^{\alpha}, \quad\left(\operatorname{det} \mathbf{M}_{\mathrm{g}}^{\alpha}\right)^{-1}=1-\operatorname{tr} \mathbf{e}_{\mathrm{g}}^{\alpha},
\end{aligned}
$$

where $\operatorname{det}(\cdot)$ is the determinant operator and $\operatorname{tr}(\cdot)$ is the trace operator.

\section{Balance of mass}

The balance of mass equation for each growing solid matrix constituent includes a mass growth function, $\mathrm{c}^{\alpha}$, that quantifies the rate of mass deposition per unit current

mass. It is decomposed into two equations by assuming that the apparent density changes only because of the elastic part of the deformation. Using (A7) and (5) $)_{3}$ and introducing the infinitesimal fluid density change $\mathrm{n}^{\mathrm{w}}, 6$ the referential continuity equations linearize to

$$
\rho^{\alpha}=\rho_{\mathrm{R}}^{\alpha}\left(1-\operatorname{tre}_{\mathrm{e}}^{\alpha}\right), \quad \rho^{\mathrm{w}}=\rho_{\mathrm{R}}^{\mathrm{w}}\left(1+\mathrm{n}^{\mathrm{W}}\right),
$$

where $\rho^{\alpha}$ is the apparent density (mass/tissue volume) and $\rho_{\mathrm{R}}^{\alpha}$ is the reference apparent

15 density. The local continuity equations (A6) become

$$
\rho_{\mathrm{R}}^{\alpha}\left(-\frac{\partial \operatorname{tr} \mathbf{e}_{\mathrm{e}}^{\alpha}}{\partial \mathrm{t}}\right)+\rho_{\mathrm{R}}^{\alpha} \operatorname{div} \mathbf{v}^{\mathrm{s}}=\rho^{\alpha} \mathrm{c}_{\mathrm{R}}^{\alpha}, \quad \rho_{\mathrm{R}}^{\mathrm{w}}\left(\frac{\partial \mathrm{n}^{\mathrm{w}}}{\partial \mathrm{t}}\right)+\rho_{\mathrm{R}}^{\mathrm{w}} \operatorname{div} \mathbf{v}^{\mathrm{w}}=0
$$

the growth continuity equations (A8) become ${ }^{7}$

\footnotetext{
${ }^{5}$ Also, the analytical results of (Klisch et al. 2000; Klisch et al. 2001; Klisch and Hoger 2003) reveal that different growth symmetries lead to different states of residual stress in a growing elastic material.

${ }^{6}$ This follows the linearization approach of (Green and Naghdi 1970).

${ }^{7}$ Eqn. $(8)_{1}$ is obtained after truncating the polynomial series representation of the exponential function in (A8).
} 


$$
\operatorname{tre}_{\mathrm{g}}^{\alpha}=\int_{\tau=\mathrm{t}_{0}}^{\mathrm{t}} \mathrm{c}_{\mathrm{R}}^{\alpha} \mathrm{d} \tau \quad \text { or } \quad \frac{\partial \operatorname{tre}_{\mathrm{g}}^{\alpha}}{\partial \mathrm{t}}=\mathrm{c}_{\mathrm{R}}^{\alpha}
$$

Also, the intrinsic incompressibility constraint (A5) becomes

$$
\mathrm{n}^{\mathrm{w}} \phi_{\mathrm{R}}^{\mathrm{w}}=\operatorname{tre}_{\mathrm{e}}^{\mathrm{p}} \phi_{\mathrm{R}}^{\mathrm{p}}+\operatorname{tre}_{\mathrm{e}}^{\mathrm{c}} \phi_{\mathrm{R}}^{\mathrm{c}}+\operatorname{tre}_{\mathrm{e}}^{\mathrm{oth}} \phi_{\mathrm{R}}^{\mathrm{oth}}
$$

where $\phi_{\mathrm{R}}^{\alpha}=\rho_{\mathrm{R}}^{\alpha} / \rho_{\mathrm{R}}^{\alpha \mathrm{T}}$ is the reference volume fraction. In the infinitesimal theory the mass

5 growth function $c_{\mathrm{R}}^{\alpha}$, defined as the rate of mass deposition per unit reference mass, is used. An alternative expression for the mixture continuity equation (A9) that is useful in solving non-equilibrium growth boundary-value problems can be derived by taking the material time-derivative of (A5) with respect to the fluid constituent and using (A6) and (A9):

$$
\phi_{\mathrm{R}}^{\mathrm{p}} c_{\mathrm{R}}^{\mathrm{p}}+\phi_{\mathrm{R}}^{\mathrm{c}} c_{\mathrm{R}}^{\mathrm{c}}+\phi_{\mathrm{R}}^{\text {oth }} \mathrm{c}_{\mathrm{R}}^{\text {oth }}=\phi_{\mathrm{R}}^{\mathrm{w}} \operatorname{div} \mathbf{v}^{\mathrm{w}}+\phi_{\mathrm{R}}^{\mathrm{p}} \operatorname{div} \mathbf{v}^{\mathrm{s}}+\phi_{\mathrm{R}}^{\mathrm{c}} \operatorname{div} \mathbf{v}^{\mathrm{s}}+\phi_{\mathrm{R}}^{\text {oth }} \operatorname{div} \mathbf{v}^{\mathrm{s}}
$$

$\underline{\text { Stresses, diffusive forces, and balance of linear momentum }}$

Neglecting body forces and inertial effects in the infinitesimal theory, the balance of linear momentum equations for the solid matrix and the fluid (A11) are

$$
\operatorname{div} \mathbf{T}^{\mathrm{s}}+\pi=\mathbf{0}, \quad \operatorname{div} \mathbf{T}^{\mathrm{W}}-\pi=\mathbf{0},
$$

15 where $\mathbf{0}$ is the zero vector and, recalling (A10) and (A12),

$$
\mathbf{T}^{\mathrm{s}}=\mathbf{T}^{\mathrm{p}}+\mathbf{T}^{\mathrm{c}}+\mathbf{T}^{\mathrm{oth}}, \quad \pi=\pi^{\mathrm{s}}=-\boldsymbol{\pi}^{\mathrm{w}}
$$

Growth laws

To obtain a complete theory, growth response functions that describe the timerates of change of $\mathbf{e}_{\mathrm{g}}^{\alpha}$ for the growing solid matrix constituents are required.

20 Mathematically, growth response functions of the general form are represented as (A13). As a precursor to establishing the growth law, here we specify growth tensors in order to solve growth boundary-value problems. It is important to note that the growth laws are 
phenomenological equations that indirectly describe chemical processes responsible for growth. For example, the mass growth functions $c_{R}^{\alpha}$ may be decomposed as a "synthesis" rate minus a "degradation" rate, and may include a mass conversion rate from one constituent to another. Also, the constants that appear in a specific growth law may be

5 parameterized by biological factors (i.e., the level of a specific growth factor).

\section{Constitutive equations}

Constitutive equations are required for the partial stresses and the diffusive force. In the model proposed here, general constitutive equations take the form (A14-A18). In (Klisch et al. 2000; Klisch and Hoger 2003), constitutive restrictions were derived from

10 thermodynamical considerations; here, we restrict the constitutive equations substantially following the assumptions discussed above. In particular, we assume that the proteoglycan stress depends on the proteoglycan, collagen, and water densities; the collagen stress is an isotropic function of the collagen elastic deformation with material constants that may evolve due to remodeling; that the determinate fluid and others

15 stresses are zero; and that the determinate diffusive force depends only on the solid matrix deformation and the diffusive velocity. In order to linearize, the free-energy functions are expressed as quadratic isotropic functions of the infinitesimal elastic strain tensors and fluid density change, and the partial derivatives are evaluated to obtain the constituent stresses and diffusive force. ${ }^{8}$ After considerable algebraic manipulation, we

20 obtain

$$
\mathbf{T}^{\mathrm{p}}=-\phi_{\mathrm{R}}^{\mathrm{p}} \mathrm{I} \mathbf{I}+\eta^{\mathrm{p}}\left(\operatorname{tre}_{\mathrm{e}}^{\mathrm{p}}\right) \mathbf{I}+\eta^{\mathrm{c}}\left(\operatorname{tre}_{\mathrm{e}}^{\mathrm{c}}\right) \mathbf{I}+\eta^{\mathrm{w}} \mathrm{n}^{\mathrm{w}} \mathbf{I}+\mathrm{T}_{\mathrm{R}}^{\mathrm{p}} \mathbf{I}
$$

\footnotetext{
${ }^{8}$ This procedure is the same as that presented in (Green and Naghdi 1970), except that the material coefficients of the collagen free energy functions are allowed to depend on the collagen remodeling parameter $\gamma$.
} 


$$
\begin{aligned}
& \mathbf{T}^{\mathrm{c}}=-\phi_{\mathrm{R}}^{\mathrm{c}} \mathrm{p} \mathbf{I}+\lambda^{\mathrm{c}}\left(\operatorname{tre}_{\mathrm{e}}^{\mathrm{c}}\right) \mathbf{I}+2 \mu^{\mathrm{c}} \mathbf{e}_{\mathrm{e}}^{\mathrm{c}}+\Gamma^{\mathrm{c}} \mathbf{I}, \\
& \mathrm{T}^{\mathrm{oth}}=-\phi_{\mathrm{R}}^{\mathrm{oth}} \mathrm{p} \mathbf{I}, \\
& \mathrm{T}^{\mathrm{w}}=-\phi_{\mathrm{R}}^{\mathrm{w}} \mathrm{p} \mathbf{I}, \\
& \pi=\hat{\Pi}\left(\mathbf{e}^{\mathrm{s}}\right) \mathbf{a},
\end{aligned}
$$

5 where $\left(\lambda^{\mathrm{c}}, \mu^{\mathrm{c}}, \Gamma^{\mathrm{c}}, \eta^{\mathrm{p}}, \eta^{\mathrm{c}}, \eta^{\mathrm{w}}\right)$ are material constants, $\mathrm{T}_{\mathrm{R}}^{\mathrm{p}}$ is the initial proteoglycan stress, and $\pi$ is a linear function of the diffusive velocity a with coefficients that may be straindependent and anisotropic since $\hat{\boldsymbol{\Pi}}\left(\mathbf{e}^{\mathrm{s}}\right)$ is a second-order tensor. The collagen material constants $\left(\lambda^{\mathrm{c}}, \mu^{\mathrm{c}}, \Gamma^{\mathrm{c}}\right)$ are parameterized by $\gamma$ so that they may change with time as remodeling occurs (formally, this requires a remodeling rate equation for $\gamma$ ). For solving

10 boundary-value problems, it is convenient to add (13-15) to obtain a stress constitutive equation for the solid matrix. First, we introduce

$$
\Gamma^{\mathrm{c}}=\mathrm{T}_{\mathrm{R}}^{\mathrm{c}}+\hat{\Gamma}
$$

where $T_{R}^{c}\left(=-T_{R}^{p}\right)$ is the initial collagen stress and the material constant $\hat{\Gamma}$ represents a change in collagen stress due to remodeling at fixed strain. Recalling (3-4), we obtain

$$
\begin{aligned}
& \mathbf{T}^{\mathrm{s}}=-\phi_{\mathrm{R}}^{\mathrm{s}} \mathrm{I} \mathbf{I}+\lambda\left(\operatorname{tre}^{\mathrm{s}}\right) \mathbf{I}+2 \mu \mathbf{e}^{\mathrm{s}}-\alpha_{1}\left(\operatorname{tre}_{\mathrm{g}}^{\mathrm{c}}\right) \mathbf{I}-\alpha_{2}\left(\operatorname{tre}_{\mathrm{g}}^{\mathrm{p}}\right) \mathbf{I}-2 \mu \mathbf{e}_{\mathrm{g}}^{\mathrm{c}}+\hat{\Gamma} \mathbf{I}, \\
& \lambda=\lambda^{\mathrm{c}}+\eta^{\mathrm{p}}+\eta^{\mathrm{c}}+\eta^{\mathrm{w}} \frac{1-\phi_{\mathrm{R}}^{\mathrm{w}}}{\phi_{\mathrm{R}}^{\mathrm{w}}}, \quad \mu=\mu^{\mathrm{c}}, \quad \alpha_{1}=\lambda^{\mathrm{c}}+\eta^{\mathrm{c}}+\eta^{\mathrm{w}} \frac{\phi_{\mathrm{R}}^{\mathrm{c}}}{\phi_{\mathrm{R}}^{\mathrm{w}}}, \\
& \alpha_{2}=\eta^{\mathrm{p}}+\eta^{\mathrm{w}} \frac{\phi_{\mathrm{R}}^{\mathrm{p}}}{\phi_{\mathrm{R}}^{\mathrm{w}}},
\end{aligned}
$$

so that the boundary-value problem may be posed in terms of the solid matrix constitutive equation of the form $\mathbf{T}^{\mathrm{s}}=\hat{\mathbf{T}}^{\mathrm{s}}\left(\mathbf{e}^{\mathrm{s}}, \mathbf{e}_{\mathrm{g}}^{\mathrm{c}}, \mathbf{e}_{\mathrm{g}}^{\mathrm{p}}, \gamma\right)$. A commonly used material constant is the solid matrix aggregate modulus $\mathrm{H}_{\mathrm{A}}$, defined as the initial slope of the equilibrium stress-strain curve in a confined compression experiment. Expressions for the aggregate moduli of the 
proteoglycan $\left(\mathrm{H}_{\mathrm{A}}^{\mathrm{p}}\right)$ and collagen $\left(\mathrm{H}_{\mathrm{A}}^{\mathrm{c}}\right)$ constituents are derived from (13-14) by assuming purely elastic deformations in (4):

$$
\mathrm{H}_{\mathrm{A}}^{\mathrm{p}}=\eta^{\mathrm{p}}+\eta^{\mathrm{c}}+\eta^{\mathrm{w}} \frac{1-\phi_{\mathrm{R}}^{\mathrm{w}}}{\phi_{\mathrm{R}}^{\mathrm{w}}}, \quad \mathrm{H}_{\mathrm{A}}^{\mathrm{c}}=\lambda^{\mathrm{c}}+2 \mu^{\mathrm{c}}
$$

and, consequently, from (19) we obtain

$$
\mathrm{H}_{\mathrm{A}}=\lambda+2 \mu=\mathrm{H}_{\mathrm{A}}^{\mathrm{p}}+\mathrm{H}_{\mathrm{A}}^{\mathrm{c}} \text {. }
$$

In this study, we are choosing constitutive equations with non-physiological assumptions (e.g., infinitesimal strains, isotropic material symmetry, initially spherical pre-stresses, material homogeneity) in order to illustrate the model and develop analytical techniques. In the discussion, we outline possible refinements of these constitutive equations that 10 may result in more accurate cartilage growth models.

In the boundary-value problems solved in this paper, we assume for simplicity that the mass of the others remains constant; recalling (8) and (4) this leads to

$$
c_{\mathrm{R}}^{\mathrm{oth}}=0 \quad \Rightarrow \quad \mathbf{e}_{\mathrm{g}}^{\mathrm{oth}}=\mathbf{0}, \quad \mathbf{e}^{\mathrm{oth}}=\mathbf{e}_{\mathrm{e}}^{\mathrm{oth}}=\mathbf{e}^{\mathrm{s}}
$$

\section{Equilibrium growth boundary-value problem}

Since we are interested in developing solution procedures for in vitro experiments, we study boundary-value problems for cartilage specimens that initially have a cylindrical geometry with radius $\mathrm{R}$ and height $\mathrm{H}$. We use cylindrical coordinates where $(r, \theta, z)$ denote the radial, circumferential, and axial coordinates and take the origin to be at the center of the specimen. To define the equilibrium boundary-value problem,

20 we make the following assumptions for a growing cartilage specimen: (1) the material properties, tissue composition, and constituent pre-stresses are initially homogeneous and given; (2) axisymmetric growth tensors are given; and (3) the grown configuration is in 
equilibrium with traction free-boundaries. Due to these assumptions, the problem is axisymmetric so that none of the variables in the theory depend on $\theta$, and the fluid pore pressure (p) and the diffusive force $(\boldsymbol{\pi})$ are zero. For an axisymmetric problem, the solid matrix strain tensor is

$$
\mathbf{e}^{\mathrm{s}}=\mathrm{e}_{\mathrm{rr}}^{\mathrm{s}} \mathbf{e}_{\mathrm{r}} \otimes \mathbf{e}_{\mathrm{r}}+\mathrm{e}_{\theta \theta}^{\mathrm{s}} \mathbf{e}_{\theta} \otimes \mathbf{e}_{\theta}+\mathrm{e}_{\mathrm{zz}}^{\mathrm{s}} \mathbf{e}_{\mathrm{z}} \otimes \mathbf{e}_{\mathrm{z}},
$$

where $\left(\mathbf{e}_{\mathrm{r}}, \mathbf{e}_{\theta}, \mathbf{e}_{\mathrm{z}}\right)$ are the unit vectors of the cylindrical coordinate system, $\otimes$ is the tensor dyadic product, and the strain components $\left(\mathrm{e}_{\mathrm{rr}}^{\mathrm{s}}, \mathrm{e}_{\theta \theta}^{\mathrm{s}}, \mathrm{e}_{\mathrm{zz}}^{\mathrm{s}}\right)$ are

$$
e_{\mathrm{rr}}^{\mathrm{s}}=\frac{\partial \mathrm{u}_{\mathrm{r}}}{\partial \mathrm{r}}, \quad \mathrm{e}_{\theta \theta}^{\mathrm{s}}=\frac{\mathrm{u}_{\mathrm{r}}}{\mathrm{r}}, \quad \mathrm{e}_{\mathrm{zz}}^{\mathrm{s}}=\frac{\partial \mathrm{u}_{\mathrm{z}}}{\partial \mathrm{z}},
$$

where $\mathrm{u}_{\mathrm{r}}$ and $\mathrm{u}_{\mathrm{z}}$ are the radial and axial components of the solid matrix displacement

10 vector. The growth tensors are assumed to take the form

$$
\mathbf{e}_{\mathrm{g}}^{\alpha}=\mathrm{e}_{\mathrm{grr}}^{\alpha} \mathbf{e}_{\mathrm{r}} \otimes \mathbf{e}_{\mathrm{r}}+\mathrm{e}_{\mathrm{g} \theta \theta}^{\alpha} \mathbf{e}_{\theta} \otimes \mathbf{e}_{\theta}+\mathrm{e}_{\mathrm{gzz}}^{\alpha} \mathbf{e}_{\mathrm{z}} \otimes \mathbf{e}_{\mathrm{z}} .
$$

For axisymmetric problems, the equilibrium equations derived from $(11)_{1}$ reduce to

$$
\frac{\partial \mathrm{T}_{\mathrm{rr}}^{\mathrm{s}}}{\partial \mathrm{r}}+\frac{1}{\mathrm{r}}\left(\mathrm{T}_{\mathrm{rr}}^{\mathrm{s}}-\mathrm{T}_{\theta \theta}^{\mathrm{s}}\right)=0, \quad \frac{1}{\mathrm{r}} \frac{\partial \mathrm{T}_{\theta \theta}^{\mathrm{s}}}{\partial \theta}=0, \quad \frac{\partial \mathrm{T}_{\mathrm{zz}}^{\mathrm{s}}}{\partial \mathrm{z}}=0
$$

while the equilibrium equations derived from $(11)_{2}$ are identically satisfied when $\mathrm{p}=0$

15 everywhere. The traction free-boundary conditions reduce to

$$
\mathrm{T}_{\mathrm{rr}}^{\mathrm{s}}(\mathrm{r}=\mathrm{R})=0, \quad \mathrm{~T}_{\mathrm{zz}}^{\mathrm{s}}(\mathrm{z}= \pm \mathrm{H} / 2)=0 .
$$

Solution to the homogeneous growth boundary-value problem

Here, the growth tensor components in (25) are assumed to be homogeneous and we restrict attention to the special case where the radial and circumferential growth tensor

20 components are identical (i.e., $\mathrm{e}_{\mathrm{grr}}^{\alpha}=\mathrm{e}_{\mathrm{g} \theta \theta}^{\alpha}$ ). In this case, homogeneous solutions exist such that the solid matrix stress is zero everywhere (so that (26) are identically satisfied) and 
the radial and circumferential solid matrix strain components are equal (i.e., $\mathrm{e}_{\mathrm{rr}}^{\mathrm{s}}=\mathrm{e}_{\theta \theta}^{\mathrm{s}}$ ). Substituting the solid matrix stress-strain equations (19) into the boundary conditions (27), we obtain the solution for the solid matrix strain components:

$$
\begin{aligned}
& \mathrm{e}_{\mathrm{rr}}^{\mathrm{s}}=\mathrm{e}_{\theta \theta}^{\mathrm{s}}=\frac{\left(2 \alpha_{1}+\lambda+2 \mu\right) \mathrm{e}_{\mathrm{grr}}^{\mathrm{c}}+2 \alpha_{2} \mathrm{e}_{\mathrm{grr}}^{\mathrm{p}}+\left(\alpha_{1}-\lambda\right) \mathrm{e}_{\mathrm{gzz}}^{\mathrm{c}}+\alpha_{2} \mathrm{e}_{\mathrm{gzz}}^{\mathrm{p}}-\hat{\Gamma}}{3 \lambda+2 \mu}, \\
& \mathrm{e}_{\mathrm{zz}}^{\mathrm{s}}=\frac{2\left(\alpha_{1}-\lambda\right) \mathrm{e}_{\mathrm{grr}}^{\mathrm{c}}+2 \alpha_{2} \mathrm{e}_{\mathrm{grr}}^{\mathrm{p}}+\left(\alpha_{1}+2 \lambda+2 \mu\right) \mathrm{e}_{\mathrm{gzz}}^{\mathrm{c}}+\alpha_{2} \mathrm{e}_{\mathrm{gzz}}^{\mathrm{p}}-\hat{\Gamma}}{3 \lambda+2 \mu} .
\end{aligned}
$$

5 This solution is then used to calculate the final tissue geometry (i.e., diameter d and height $h$ ) by integrating (28) to obtain the solid matrix displacement vector using (24); the proteoglycan and collagen elastic strain tensors using (4), (23), and (25); the infinitesimal fluid density change using (9); the final volume fractions using (6); and the proteoglycan and collagen stresses using (13-14). Final tissue volume was calculated using the volume

10 formula for a cylinder.

Solution to the nonhomogeneous growth boundary-value problem

It has been shown that for a dynamic unconfined compression protocol, nonhomogeneous proteoglycan mass deposition is best correlated with the spatial profile of relative fluid velocity, being least at the center of the specimen and increasing with

15 radial coordinate $\mathrm{r}$ (Buschmann et al. 1999). Motivated by these findings, we consider a special case where the growth tensor components are zero at $\mathrm{r}=0$ and linearly increasing with the radial coordinate $\mathrm{r}$. Also, we restrict attention to the special case where the radial and circumferential growth tensor components are identical. In this case, the growth tensors are

$$
\mathbf{e}_{\mathrm{g}}^{\alpha}=\mathrm{g}_{\mathrm{r}}^{\alpha} \mathbf{e}_{\mathrm{r}} \otimes \mathbf{e}_{\mathrm{r}}+\mathrm{g}_{\mathrm{r}}^{\alpha} \mathbf{r e}_{\theta} \otimes \mathbf{e}_{\theta}+\mathrm{g}_{\mathrm{z}}^{\alpha} \mathbf{r e}_{\mathrm{z}} \otimes \mathbf{e}_{\mathrm{z}}
$$


where $\left(\mathrm{g}_{\mathrm{r}}^{\alpha}, \mathrm{g}_{\mathrm{z}}^{\alpha}\right)$ are constants. Since there is no z-dependence in the solution, the only nontrivial equilibrium equation is (26) $)_{1}$. Using the strain-displacement relations (24), the growth tensors (29), the stress-strain equations (19), and the boundary condition $(27)_{2}$, we obtain the governing ordinary differential equation for the solid matrix radial 5 displacement:

$$
\begin{aligned}
& \frac{\partial^{2} \mathrm{u}_{\mathrm{r}}}{\partial \mathrm{r}^{2}}+\frac{1}{\mathrm{r}} \frac{\partial \mathrm{u}_{\mathrm{r}}}{\partial \mathrm{r}}-\frac{\mathrm{u}_{\mathrm{r}}}{\mathrm{r}^{2}}=\mathrm{A}, \\
& \mathrm{A}=\frac{1}{2(\lambda+2 \mu)}\left[\alpha_{1}\left(2 \mathrm{~g}_{\mathrm{r}}^{\mathrm{c}}+\mathrm{g}_{\mathrm{z}}^{\mathrm{c}}\right)+\alpha_{2}\left(2 \mathrm{~g}_{\mathrm{r}}^{\mathrm{p}}+\mathrm{g}_{\mathrm{z}}^{\mathrm{p}}\right)-\lambda \mathrm{g}_{\mathrm{z}}^{\mathrm{c}}+(\lambda+2 \mu) \mathrm{g}_{\mathrm{r}}^{\mathrm{c}}\right],
\end{aligned}
$$

for which an exact solution exists:

$$
\mathrm{u}_{\mathrm{r}}=\frac{\mathrm{Ar}^{2}}{3}+\frac{\mathrm{C}_{1}}{\mathrm{r}}+\mathrm{C}_{2} \mathrm{r} \text {, }
$$

where $\mathrm{C}_{1}$ and $\mathrm{C}_{2}$ are constants of integration. Imposing the additional boundary

10 condition that the solid matrix radial displacement is zero at $r=0$ leads to $C_{1}=0$. Imposing the boundary condition (27) allows for the determination of $\mathrm{C}_{2}$; thus,

$$
\begin{aligned}
& \mathrm{C}_{1}=0, \quad \mathrm{C}_{2}=\frac{\mathrm{R}}{3 \lambda+2 \mu}\left[-\left(\frac{5}{3} \lambda+\frac{4}{3} \mu\right) \mathrm{A}+\alpha_{1}\left(2 \mathrm{~g}_{\mathrm{r}}^{\mathrm{c}}+\mathrm{g}_{\mathrm{z}}^{\mathrm{c}}\right)\right. \\
& \left.+\alpha_{2}\left(2 g_{r}^{p}+g_{z}^{p}\right)-\lambda g_{z}^{c}+(\lambda+2 \mu) g_{r}^{c}-\hat{\Gamma}\right] \text {. }
\end{aligned}
$$

This solution is then used to calculate the final tissue geometry (i.e., diameter $\mathrm{d}$ and height $\mathrm{h}$ where $\mathrm{h}$ is a function of $\mathrm{r}$ ) by evaluating (31) at $\mathrm{r}=\mathrm{R}$ and by integrating the

15 derived expression for $\partial \mathrm{u}_{\mathrm{z}} / \partial \mathrm{z}$ with respect to $\mathrm{z}$ to calculate $\mathrm{u}_{\mathrm{z}}$ at $\mathrm{z}=\mathrm{H} / 2$ (which depends on r); and the other output variables are calculated as discussed above. Final tissue volume was calculated by integrating a differential volume element over the appropriate limits of integration. 


\section{Non-equilibrium growth boundary-value problem}

Since the mechanical effects due to growth and to typical in vivo or in vitro mechanical loads occur over time scales that differ by several orders of magnitude, we hypothesized that a time increment may be chosen over which the dynamic mechanical

5 effects of growth may be neglected. Thus, we consider a non-equilibrium growth boundary-value problem with growth rates that lie at the high end of those reported in the literature (e.g., see (Mauck et al. 2000)), in order to best support any conclusions regarding the relative time scales of growth and applied mechanical loads. We consider growth in a radially confined chamber because it describes a common experimental tissue

10 engineering protocol (as discussed in the introduction) and because we plan on analyzing these types of growth experiments in the future using the finite deformation theory in order to reduce the analysis to a one-dimensional problem. Furthermore, using a radially confined configuration allows us to compare the governing partial differential equations to those derived for confined compression using the biphasic model.

15 We use cylindrical coordinates $(\mathrm{r}, \theta, \mathrm{z})$ and take the origin to be at the center of the specimen. To define the boundary-value problem, we make the following assumptions: (1) the material properties, tissue composition, and constituent pre-stresses are initially homogeneous and given; (2) isotropic growth tensors and time-independent mass growth functions are assumed; (3) the specimen is radially confined at $\mathrm{r}=\mathrm{R}$ and has a traction

20 free-boundary at its top and bottom surfaces; (4) the top and bottom surfaces are in contact with a physiologic saline and the fluid may flow freely through these surfaces. Due to these assumptions, the solid matrix displacement, solid matrix strain, and all velocity vectors are one-dimensional (i.e., they only have a z-component). As with the 
confined compression biphasic model solution (Mow et al. 1980), the problem is "onedimensional" so that none of the variables in the theory depend on $r$ or $\theta$ and the governing equations can be reduced to obtain decoupled partial differential equations for the solid matrix displacement and fluid pore pressure. Thus, we set

$$
\mathbf{u}^{\mathrm{s}}=\mathrm{u}(\mathrm{z}, \mathrm{t}) \mathbf{e}_{\mathrm{z}}, \quad \mathrm{p}=\mathrm{p}(\mathrm{z}, \mathrm{t}), \quad \mathbf{v}^{\mathrm{s}}=\frac{\partial \mathrm{u}}{\partial \mathrm{t}} \mathbf{e}_{\mathrm{z}}, \quad \mathbf{v}^{\mathrm{w}}=\mathrm{v}^{\mathrm{w}} \mathbf{e}_{\mathrm{z}} \quad \mathbf{e}^{\mathrm{s}}=\frac{\partial \mathrm{u}}{\partial \mathrm{z}} \mathbf{e}_{\mathrm{z}} \otimes \mathbf{e}_{\mathrm{z}}
$$

The isotropic growth tensors are expressed as

$$
\mathbf{e}_{\mathrm{g}}^{\alpha}=\mathrm{e}_{\mathrm{g}}^{\alpha} \mathbf{I}\left(\Rightarrow \operatorname{tr} \mathbf{e}_{\mathrm{g}}^{\alpha}=3 \mathrm{e}_{\mathrm{g}}^{\alpha}\right)
$$

The non-trivial linear momentum equations derived from (11) are

$$
\frac{\partial \mathrm{T}_{\mathrm{zz}}^{\mathrm{s}}}{\partial \mathrm{z}}+\pi_{\mathrm{z}}=0, \quad \frac{\partial \mathrm{T}_{\mathrm{zz}}^{\mathrm{W}}}{\partial \mathrm{z}}-\pi_{\mathrm{z}}=0
$$

10 Here, we assume that the diffusive force is strain-independent:

$$
\pi_{\mathrm{z}}=\frac{\left(\phi_{\mathrm{R}}^{\mathrm{w}}\right)^{2}}{\mathrm{k}} \mathrm{a}
$$

where $\mathrm{k}$ is the permeability constant and a is the $\mathrm{z}$-component of the diffusive velocity. Due to symmetry about the $\mathrm{z}=0$ plane, the solid matrix displacement and velocity vectors are zero at $\mathrm{z}=0$ :

$$
\mathrm{u}(0, \mathrm{t})=0, \quad \mathrm{v}^{\mathrm{s}}(0, \mathrm{t})=0, \quad \mathrm{v}^{\mathrm{w}}(0, \mathrm{t})=0
$$

The fluid pore pressure and the solid matrix stress are assumed to be zero at the top and bottom surfaces. Consequently, the initial and boundary conditions are

$$
\mathrm{u}(\mathrm{z}, 0)=0, \quad \mathrm{p}(\mathrm{z}, 0)=0, \quad \mathrm{~T}_{\mathrm{zz}}^{\mathrm{s}}(\mathrm{H} / 2, \mathrm{t})=0, \quad \mathrm{p}(\mathrm{H} / 2, \mathrm{t})=0 .
$$

Solution to the non-equilibrium growth boundary-value problem 


$$
\begin{aligned}
& 3 \frac{\partial \mathrm{e}_{\mathrm{g}}^{\alpha}}{\partial \mathrm{t}}=\mathrm{c}_{\mathrm{R}}^{\alpha}, \quad \rho_{\mathrm{R}}^{\mathrm{w}} \frac{\partial \mathrm{n}^{\mathrm{w}}}{\partial \mathrm{t}}+\rho_{\mathrm{R}}^{\mathrm{w}} \frac{\partial \mathrm{v}^{\mathrm{w}}}{\partial \mathrm{z}}=0, \\
& \phi_{\mathrm{R}}^{\mathrm{p}} \mathrm{c}_{\mathrm{R}}^{\mathrm{p}}+\phi_{\mathrm{R}}^{\mathrm{c}} \mathrm{c}_{\mathrm{R}}^{\mathrm{c}}=\phi_{\mathrm{R}}^{\mathrm{w}} \frac{\partial \mathrm{v}^{\mathrm{w}}}{\partial \mathrm{z}}+\left(\phi_{\mathrm{R}}^{\mathrm{p}}+\phi_{\mathrm{R}}^{\mathrm{c}}+\phi_{\mathrm{R}}^{\mathrm{oth}}\right) \frac{\partial^{2} \mathrm{u}}{\partial \mathrm{z} \partial \mathrm{t}},
\end{aligned}
$$

and the reduced intrinsic incompressibility constraint:

$$
\phi_{\mathrm{R}}^{\mathrm{w}} \mathrm{n}^{\mathrm{w}}=\phi_{\mathrm{R}}^{\mathrm{p}}\left(\frac{\partial \mathrm{u}}{\partial \mathrm{z}}-3 \mathrm{e}_{\mathrm{g}}^{\mathrm{p}}\right)+\phi_{\mathrm{R}}^{\mathrm{c}}\left(\frac{\partial \mathrm{u}}{\partial \mathrm{z}}-3 \mathrm{e}_{\mathrm{g}}^{\mathrm{c}}\right)+\phi_{\mathrm{R}}^{\mathrm{oth}} \frac{\partial \mathrm{u}}{\partial \mathrm{z}}
$$

Integrating (39) $)_{3}$ from 0 to $\mathrm{z}$ and recalling (37), we obtain

$$
\phi_{\mathrm{R}}^{\mathrm{w}} \mathrm{v}^{\mathrm{w}}=-\left(\phi_{\mathrm{R}}^{\mathrm{p}}+\phi_{\mathrm{R}}^{\mathrm{c}}+\phi_{\mathrm{R}}^{\mathrm{oth}}\right) \frac{\partial \mathrm{u}}{\partial \mathrm{t}}+\phi_{\mathrm{R}}^{\mathrm{p}} \mathrm{c}_{\mathrm{R}}^{\mathrm{p}}+\phi_{\mathrm{R}}^{\mathrm{c}} \mathrm{c}_{\mathrm{R}}^{\mathrm{c}}
$$

The axial components of the solid matrix stress, fluid stress, and diffusive force are derived from (19), (16) and (36) using (33-34):

$$
\begin{aligned}
& \mathrm{T}_{\mathrm{zz}}^{\mathrm{s}}=-\phi_{\mathrm{R}}^{\mathrm{s}} \mathrm{p}+(\lambda+2 \mu) \frac{\partial \mathrm{u}}{\partial \mathrm{z}}-3 \alpha_{1} \mathrm{e}_{\mathrm{g}}^{\mathrm{c}}-3 \alpha_{2} \mathrm{e}_{\mathrm{g}}^{\mathrm{p}}-2 \mu \mathrm{e}_{\mathrm{g}}^{\mathrm{c}}, \\
& \mathrm{T}_{\mathrm{zz}}^{\mathrm{w}}=-\phi_{\mathrm{R}}^{\mathrm{w}} \mathrm{p}, \quad \pi_{\mathrm{z}}=\frac{\left(\phi_{\mathrm{R}}^{\mathrm{w}}\right)^{2}}{\mathrm{k}}\left(\mathrm{v}^{\mathrm{w}}-\frac{\partial \mathrm{u}}{\partial \mathrm{t}}\right)
\end{aligned}
$$

The derivation of the governing partial differential equations proceeds as follows. The

10 fluid velocity $\mathrm{v}^{\mathrm{w}}$ is solved from (41) and used in the diffusive force equation (42) 3 . Then, the stresses and diffusive force from (42) are substituted into (35). The resulting equations can be decoupled, yielding

$$
\frac{\partial^{2} \mathrm{u}}{\partial \mathrm{z}^{2}}=\frac{1}{\mathrm{H}_{\mathrm{A}} \mathrm{k}}\left\{\frac{\partial \mathrm{u}}{\partial \mathrm{t}}-\left(\phi_{\mathrm{R}}^{\mathrm{p}} \mathrm{c}_{\mathrm{R}}^{\mathrm{p}}+\phi_{\mathrm{R}}^{\mathrm{c}} \mathrm{c}_{\mathrm{R}}^{\mathrm{c}}\right) \mathrm{z}\right\}, \quad \frac{\partial \mathrm{p}}{\partial \mathrm{z}}=\mathrm{H}_{\mathrm{A}} \frac{\partial^{2} \mathrm{u}}{\partial \mathrm{z}^{2}},
$$

where the aggregate modulus $\mathrm{H}_{\mathrm{A}}$ is defined in (19-20). Equation (43) $)_{2}$ can be integrated 15 using the boundary condition $(38)_{4}$ to obtain:

$$
\mathrm{p}(\mathrm{z}, \mathrm{t})=\mathrm{H}_{\mathrm{A}}\left\{\frac{\partial \mathrm{u}}{\partial \mathrm{z}}(\mathrm{z}, \mathrm{t})-\frac{\partial \mathrm{u}}{\partial \mathrm{z}}(\mathrm{H} / 2, \mathrm{t})\right\} .
$$


Thus, the solution procedure is to solve (43) for the solid matrix displacement and use the result in (44) to solve for the fluid pore pressure. The above equations reduce to those for the confined compression analysis using the biphasic model (Mow et al. 1980) by setting all growth terms to zero. $(38)_{3}$ are used. Using $(42)_{1}$, the boundary condition $(38)_{3}$ leads to

$$
\frac{\partial \mathrm{u}}{\partial \mathrm{z}}(\mathrm{H} / 2, \mathrm{t})=\frac{1}{\mathrm{H}_{\mathrm{A}}}\left\{\left(3 \alpha_{1}+2 \mu\right) \mathrm{e}_{\mathrm{g}}^{\mathrm{c}}+3 \alpha_{2} \mathrm{e}_{\mathrm{g}}^{\mathrm{p}}\right\} .
$$

To simplify the solution procedure, we choose the mass growth functions $c_{R}^{\alpha}$ to be constant with time. Consequently, the partial differential equation for the solid matrix 10 displacement and the initial and boundary conditions are:

$$
\begin{aligned}
& \frac{\partial^{2} \mathrm{u}}{\partial \mathrm{z}^{2}}=\frac{1}{\mathrm{H}_{\mathrm{A}} \mathrm{k}}\left\{\frac{\partial \mathrm{u}}{\partial \mathrm{t}}-\left(\phi_{\mathrm{R}}^{\mathrm{p}} \mathrm{c}_{\mathrm{R}}^{\mathrm{p}}+\phi_{\mathrm{R}}^{\mathrm{c}} \mathrm{c}_{\mathrm{R}}^{\mathrm{c}}\right) \mathrm{z}\right\}, \quad \mathrm{u}(\mathrm{z}, 0)=0, \\
& \mathrm{u}(0, \mathrm{t})=0, \quad \frac{\partial \mathrm{u}}{\partial \mathrm{z}}(\mathrm{H} / 2, \mathrm{t})=\frac{1}{\mathrm{H}_{\mathrm{A}}}\left\{\left(\alpha_{1}+\frac{2}{3} \mu\right) \mathrm{c}_{\mathrm{R}}^{\mathrm{c}}+\alpha_{2} \mathrm{c}_{\mathrm{R}}^{\mathrm{p}}\right\} \mathrm{t} .
\end{aligned}
$$

This is a nonhomogeneous partial differential equation with a nonhomogeneous, linear, time-dependent boundary condition without an analytical solution.

To solve (46), we obtained a numerical solution by assuming a time increment

$15(0<\tau<1)$ corresponding to $\left(\mathrm{t}_{1}<\mathrm{t}<\mathrm{t}_{2}\right)$ over which the boundary condition $(46)_{4}$ is constant, and equal to its value at the end of the prescribed time increment $\left(\tau=1 ; t=t_{2}\right)$. The resulting partial differential equation has an exact solution for the time increment:

$$
\begin{aligned}
& \mathrm{u}(\mathrm{z}, \tau)=\mathrm{u}_{\mathrm{E}}(\mathrm{z})+\sum_{\mathrm{n}=1}^{\infty} \mathrm{B}_{\mathrm{n}} \sin \frac{(2 \mathrm{n}-1) \pi \mathrm{z}}{\mathrm{H}} \mathrm{e}^{-\mathrm{kH} \mathrm{H}_{\mathrm{A}}\left[\frac{(2 \mathrm{n}-1) \pi}{\mathrm{H}}\right]^{2} \tau}, \\
& \mathrm{u}_{\mathrm{E}}(\mathrm{z})=-\frac{1}{6} \frac{\phi_{\mathrm{R}}^{\mathrm{p}} \mathrm{c}_{\mathrm{R}}^{\mathrm{p}}+\phi_{\mathrm{R}}^{\mathrm{c}} \mathrm{c}_{\mathrm{R}}^{\mathrm{c}}}{\mathrm{kH}_{\mathrm{A}}} \mathrm{z}^{3}+\left(\mathrm{A}+\frac{1}{2} \frac{\phi_{\mathrm{R}}^{\mathrm{p}} \mathrm{c}_{\mathrm{R}}^{\mathrm{p}}+\phi_{\mathrm{R}}^{\mathrm{c}} \mathrm{c}_{\mathrm{R}}^{\mathrm{c}}}{\mathrm{kH}_{\mathrm{A}}} \frac{\mathrm{H}^{2}}{4}\right) \mathrm{z},
\end{aligned}
$$




$$
\begin{aligned}
& A=\frac{1}{H_{A}}\left\{\left(\alpha_{1}+\frac{2}{3} \mu\right) c_{R}^{c}+\alpha_{2} c_{R}^{p}\right\} t_{2}, \\
& B_{n}=\frac{4}{H} \int_{0}^{H / 2}\left[f(z)-u_{E}(z)\right] \sin \frac{(2 n-1) \pi z}{H} d z,
\end{aligned}
$$

where $f(z)=u(z, \tau=0)$ is the initial condition corresponding to the solution from the previous time increment and $\mathrm{A}=\partial \mathrm{u} / \partial \mathrm{z}\left(\mathrm{H} / 2, \mathrm{t}_{2}\right)$ represents the boundary condition at

5 the end of the time increment. Thus, to solve the non-equilibrium problem, a time increment is chosen and the solution (47) is obtained in an iterative fashion by updating the initial and boundary conditions. Convergence studies indicated that ten terms in the summation were sufficient and that the integral defining $B_{n}$ could be evaluated using the trapezoidal rule. The numerical solution was obtained using Mathematica.

To solve the problems outlined above, values for the following model parameters must be specified: constituent volume fractions/pre-stresses, material constants for the proteoglycan/collagen stresses, and the permeability constant. Experimental measures of tissue composition, confined compression aggregate modulus, and permeability were

15 available for a typical calf bovine cartilage explant harvested from the patellofemoral groove (Williamson et al. 2001). Using this data, the proteoglycan stress component $T_{R}^{p}$ was determined using the model of (Basser et al. 1998). That approach uses a twocompartmental model for the fluid constituent: an interfibrillar compartment contained in the collagen fibers, and an extrafibrillar compartment surrounding the collagen fibers.

20 The proteoglycans reside in the extrafibrillar water compartment; thus, an effective fixed charge density is calculated by dividing the total fixed charge density by the extrafibrillar water mass. The relationship between proteoglycan swelling stress and effective fixed 
charge density is assumed to be the same as that of extracted proteoglycans. The swelling stress (defined per unit area of the extrafibrillar water) is multiplied by the extrafibrillar water volume fraction to obtain the proteoglycan stress defined per unit mixture area. The input parameters are the following measures of tissue composition: wet weight mass

$5 \mathrm{~m}_{\mathrm{WW}}$, dry weight mass $\mathrm{m}_{\mathrm{DW}}, \mathrm{GAG}$ mass $\mathrm{m}_{\mathrm{G}}$, and hydroxyproline content $\mathrm{m}_{\mathrm{C}}$.

Then, using the experimental solid matrix aggregate modulus and methods in earlier studies (Chen and Sah 2001; Klisch et al. 2003), the proteoglycan material constants are calculated as follows. First, curves of the proteoglycan stress component $\mathrm{T}^{\mathrm{p}}$ vs. the confined compression strain $\varepsilon$ are generated. In confined compression, it is

10 assumed that only water mass changes as fluid flows out of the tissue. For a given $\varepsilon, \mathrm{m}_{\mathrm{ww}}$ is reduced by the volume change (since the density of the fluid is assumed to equal 1 $\mathrm{g} / \mathrm{cm}^{3}$ ) and the model is applied to solve for $\mathrm{T}^{\mathrm{p}}$. From the calculated $\mathrm{T}^{\mathrm{p}}$ vs. $\varepsilon$ curve, the proteoglycan aggregate modulus $\mathrm{H}_{\mathrm{A}}^{\mathrm{p}}$ is calculated as

$$
\mathrm{H}_{\mathrm{A}}^{\mathrm{p}}=\frac{\Delta \mathrm{T}^{\mathrm{p}}}{\varepsilon},
$$

15 where convergence studies indicated that $\varepsilon=1 \%$ was sufficient. Then, the material constants $\left(\eta^{\mathrm{p}}, \eta^{\mathrm{c}}\right)$ are estimated using a similar procedure. First, $\mathrm{m}_{\mathrm{G}}$ and, consequently, $\mathrm{m}_{\mathrm{WW}}$ and $\mathrm{m}_{\mathrm{DW}}$ are increased, the model is applied, and $\eta^{\mathrm{p}}$ is calculated by approximating the partial derivative of (13) with respect to tre $\mathbf{e}_{\mathrm{e}}^{\mathrm{p}}$ and using (6) :

$$
\eta^{\mathrm{p}}=-\frac{\mathrm{m}_{\mathrm{p}}}{\Delta \mathrm{m}_{\mathrm{p}}} \Delta \mathrm{T}^{\mathrm{p}}
$$

20 Next, $\mathrm{m}_{\mathrm{C}}$ and, consequently, $\mathrm{m}_{\mathrm{ww}}$ and $\mathrm{m}_{\mathrm{DW}}$ are increased, the model is applied, and $\eta^{\mathrm{c}}$ is calculated in a similar fashion: 


$$
\eta^{\mathrm{c}}=-\frac{\mathrm{m}_{\mathrm{c}}}{\Delta \mathrm{m}_{\mathrm{c}}} \Delta \mathrm{T}^{\mathrm{p}}
$$

Using the calculated values of $\left(H_{A}^{p}, \eta^{p}, \eta^{c}\right), \eta^{w}$ is calculated from $(20)_{1}$ and the collagen aggregate modulus $\mathrm{H}_{\mathrm{A}}^{\mathrm{c}}$ is calculated from $(21)_{2}$. The collagen material constants $\left(\lambda^{\mathrm{c}}, \mu^{\mathrm{c}}\right)$ were determined as in an earlier study (Klisch et al. 2003) by assuming a solid matrix

5 Poisson's ratio of 0.11 reported for bovine cartilage explants (Wong et al. 2000). The input parameters used are listed in Table 1.

\section{Parameter studies}

For both equilibrium and non-equilibrium problems, we assumed an initial diameter and height of 2 and $1 \mathrm{~mm}$, respectively.

\section{$10 \quad$ Equilibrium solutions}

For homogeneous growth, the following problems were solved to investigate the relative effects of collagen remodeling activity, growth symmetry, and differential growth:

ISO $\left(\mathrm{e}_{\mathrm{g}}^{\mathrm{p}}>\right)$ : isotropic growth $\left(\operatorname{tre}_{\mathrm{g}}^{\mathrm{p}}=0.30, \operatorname{tre}_{\mathrm{g}}^{\mathrm{c}}=0.15\right)$;

ISO - R $\left(\mathrm{e}_{\mathrm{g}}^{\mathrm{p}}>\right)$ : isotropic growth + remodeling $\left(\operatorname{tre}_{\mathrm{g}}^{\mathrm{p}}=0.30, \operatorname{tre}_{\mathrm{g}}^{\mathrm{c}}=0.15\right)$;

$\operatorname{PLAN}\left(\mathrm{e}_{\mathrm{g}}^{\mathrm{p}}>\right)$ : planar growth $\left(\operatorname{tre}_{\mathrm{g}}^{\mathrm{p}}=0.30, \operatorname{tre}_{\mathrm{g}}^{\mathrm{c}}=0.15\right)$;

ISO $\left(\mathrm{e}_{\mathrm{g}}^{\mathrm{c}}>\right)$ : isotropic growth $\left(\operatorname{tre}_{\mathrm{g}}^{\mathrm{p}}=0.15, \operatorname{tre}_{\mathrm{g}}^{\mathrm{c}}=0.30\right)$;

ISO - R $\left(e_{g}^{c}>\right)$ : isotropic growth + remodeling $\left(\operatorname{tre}_{\mathrm{g}}^{\mathrm{p}}=0.15, \operatorname{tre}_{\mathrm{g}}^{\mathrm{c}}=0.30\right)$.

Recalling (8), the total mass deposited for either constituent is

$$
\text { deposited mass }=\rho_{\mathrm{R}}^{\alpha} \int_{\mathrm{V}}\left(\int_{\tau=t_{0}}^{\mathrm{t}} \mathrm{c}_{\mathrm{R}}^{\alpha} \mathrm{d} \tau\right) \mathrm{dV}=\rho_{\mathrm{R}}^{\alpha} \int_{\mathrm{V}} \operatorname{tre} \mathrm{e}_{\mathrm{g}}^{\alpha} \mathrm{dV} \text {. }
$$


Thus, cases with $\left(\operatorname{tre}_{\mathrm{g}}^{\mathrm{p}}=0.30, \operatorname{tre}_{\mathrm{g}}^{\mathrm{c}}=0.15\right)$ represent a $30 \%$ increase in proteoglycan mass and a $15 \%$ increase in collagen mass, whereas cases with $\left(\operatorname{tre}_{\mathrm{g}}^{\mathrm{p}}=0.15, \operatorname{tre}_{\mathrm{g}}^{\mathrm{c}}=0.30\right)$ represent a $15 \%$ increase in proteoglycan mass and a $30 \%$ increase in collagen mass. Isotropic growth does not result in a preferential direction for mass deposition so that

$5 \mathrm{e}_{\mathrm{grr}}^{\alpha}=\mathrm{e}_{\mathrm{g} \theta \theta}^{\alpha}=\mathrm{e}_{\mathrm{gzz}}^{\alpha}$ in (25). The planar growth case results in a preferential direction for mass deposition in the radial direction; we chose $\mathrm{e}_{\mathrm{grr}}^{\alpha}=\mathrm{e}_{\mathrm{g} \theta \theta}^{\alpha}, \mathrm{e}_{\mathrm{gzz}}^{\alpha}=0$ in (25) such that $\operatorname{tre}_{\mathrm{g}}^{\mathrm{p}}=0.30, \operatorname{tre}_{\mathrm{g}}^{\mathrm{c}}=0.15$. For the cases with remodeling, the collagen material constants $\left(\mu^{\mathrm{c}}, \Gamma^{\mathrm{c}}\right)$ were each increased by $10 \%$ to represent a stiffening of the collagen network.

The equilibrium solution to one nonhomogeneous growth case is presented, in

10 which the constants $\left(\mathrm{g}_{\mathrm{r}}^{\alpha}, \mathrm{g}_{\mathrm{z}}^{\alpha}\right)$ in (29) were selected using (51) to correspond to the same mass deposition as the homogeneous case ISO $\left(\mathrm{e}_{\mathrm{g}}^{\mathrm{c}}>\right)$ :

ISO - NH $\left(\mathrm{e}_{\mathrm{g}}^{\mathrm{c}}>\right)$ : nonhomogeneous isotropic growth.

\section{$\underline{\text { Non-equilibrium solutions }}$}

We assumed the same reference configuration as that chosen for the equilibrium

15 problems, and specified mass growth functions $\mathrm{c}_{\mathrm{R}}^{\alpha}$ to correspond to a $30 \%$ increase in proteoglycan mass and a $15 \%$ increase in collagen mass over a time of one day. We chose time increments of 5 minutes and solved the problem numerically as discussed above. Although we also obtained an exact solution for the time-dependent response to equilibrium after the growth process ends at one day, these results are not presented as

20 the tissue reached equilibrium over a time scale on the order of seconds. 
Klisch et al., "A cartilage growth mixture model for infinitesimal strains ..."

\section{RESULTS}

In the figures and tables, the case REF refers to the reference configuration with volume fractions and constituent pre-stresses listed in Table 1.

\section{Equilibrium solutions}

Tissue composition and constituent pre-stresses depended on remodeling activity, growth symmetry, growth heterogeneity, and differential growth. For homogeneous growth, the solid matrix strain and, consequently, the constituent elastic strains, volume fractions, and stresses were homogeneous and the solid matrix stress was zero (Fig. 1). For nonhomogeneous growth (ISO- $\mathrm{NH}\left(\mathrm{e}_{\mathrm{g}}^{\mathrm{c}}>\right)$ ), the solid matrix strain and,

10 consequently, the constituent volume fractions, pre-stresses, and solid matrix stress varied with radial position $\mathrm{r}$ (Fig. 2). Tissue geometry depended on remodeling activity, growth symmetry, growth heterogeneity, and differential growth (Fig. 3). The final geometry was cylindrical except for the non-homogeneous growth case ( ISO - NH $\left(\mathrm{e}_{\mathrm{g}}^{\mathrm{c}}>\right)$ ), where the axial displacement of the solid matrix increased with radial

15 position $r$ (result not shown).

\section{Non-equilibrium solution}

The results for the non-equilibrium growth boundary-value problem indicate that the tissue is nearly in equilibrium at all time points. At the end of the growth process (one day), the solid matrix strain was nonhomogeneous (Fig. 4); however, the difference

20 between the strain values at the top $(\mathrm{z}=\mathrm{H} / 2)$ and middle $(\mathrm{z}=0)$ surfaces was $0.005 \%$. The average solid matrix strain was calculated as the displacement of the surface $(\mathrm{z}=\mathrm{H} / 2)$ divided by the height of the symmetrical control volume $(\mathrm{H} / 2)$, and increased nearly linearly with time (Fig. 4). Consequently, the averaged volume fractions, velocities, and 
Klisch et al., "A cartilage growth mixture model for infinitesimal strains ..."

stresses also increased nearly linearly with time (results not shown). The volume fractions were nonhomogeneous (Fig. 5), with proteoglycan and collagen contents highest at $\mathrm{z}=0$ and water content highest at $\mathrm{z}=\mathrm{H} / 2$. These results indicate that at the end of the growth process, water will flow towards the center of the specimen to reach

5 equilibrium (this was verified by direct solution although the results are not presented). The velocities were nonhomogeneous (Fig. 6); the diffusive velocity profile indicates that fluid is flowing out of the tissue during the growth process. The fluid and solid matrix stresses were nonhomogeneous (Fig. 6).

\section{DISCUSSION}

We have presented a CGM model for infinitesimal strains and solved boundaryvalue problems chosen in order to elucidate how the CGM model may ultimately be used with in vitro growth experiments. The results reveal that the CGM model has the capability to predict the evolution of tissue composition, stresses, and geometry of growing cartilage.

The solutions have possible implications for tissue engineering experiments. For example, the results suggest that the CGM model may be used to identify stages of growth experiments: one to achieve a geometry needed to repair a cartilage defect in vivo, and another to achieve an enhancement of structural and functional properties. For homogeneous growth, the solutions reveal that the cartilage matrix is homogeneous and

20 that the solid matrix is not residually stressed. The two homogeneous growth cases with a greater proteoglycan mass growth function, ISO $\left(\mathrm{e}_{\mathrm{g}}^{\mathrm{p}}>\right)$ and $\operatorname{PLAN}\left(\mathrm{e}_{\mathrm{g}}^{\mathrm{p}}>\right)$, resulted in the greatest increase in tissue volume. Thus, by identifying a mechanical loading protocol to produce these types of growth, the tissue engineer may be able to grow a construct to a 
specified volume in order to fill a defect in vivo. On the other hand, homogeneous growth with a greater collagen mass growth function and remodeling activity, ISO - R ( $\left.e_{\mathrm{g}}^{\mathrm{c}}>\right)$, resulted in the least increase of tissue volume, the greatest solid matrix content, and the second-greatest constituent pre-stresses. Greater proteoglycan and

5 collagen pre-stresses may likely to an enhancement of biomechanical function (such as compressive, tensile, and shear properties) due to the nonlinear stress-strain behavior of the cartilage solid matrix. Furthermore, greater solid matrix content may lead to a lower permeability. Since mature cartilage has a higher solid content, higher elastic moduli, and lower permeability than immature constructs, these results suggest that by identifying a

10 mechanical loading protocol to produce this type of growth, the tissue engineer may be able to grow a construct with the desired compositional and biomechanical properties.

The results also suggest that the CGM model may be used to predict how dynamic mechanical loading affects the development of nonhomogeneous properties during in vitro growth. The type of nonhomogeneous growth that was chosen here was intended to

15 model the results of (Buschmann et al. 1999) in which a dynamic compression loading protocol revealed that proteoglycan mass deposition was most closely correlated with the magnitude of diffusive velocity, increasing with radial position. The results predict that non-uniform growth leads to a nonhomogeneous specimen with a residually stressed solid matrix, in agreement with previous studies. Native cartilage is nonhomogeneous;

20 for example, the superficial region of cartilage has a lower aggregate modulus, higher permeability, and higher water content than the middle and deep regions (Schinagl et al. 1997). It has been shown that these nonhomogeneous properties affect the solid matrix compaction, fluid pressure, and fluid flow throughout the tissue in confined compression 
(Wang et al. 2001). In order to design a construct that has the nonhomogeneous properties of native cartilage, it is likely that a combination of different dynamic loading protocols is necessary. It may be possible to experimentally determine model parameters for specific dynamic loading protocols such as compression, tension, and shear, and then

5 use the CGM model to predict a sequential combination of these protocols to produce the desired nonhomogeneous properties in place of time consuming and costly experiments. To best mimic the nonhomogeneous properties of native cartilage, these methods may be combined with recent experiments with constructs grown from chondrocytes with different phenotypes; for example, stratified cartilage constructs have been fabricated in

10 vitro by harvesting cells from both the superficial and middle regions of cartilage explants (Klein et al. 2003).

The solution to the non-equilibrium growth boundary-value problem suggests the manner in which the CGM model may be used in the future to quantify the biomechanics of growth in vitro. The mass growth functions that were chosen in the present study

15 reflect an upper bound based on previous experimental results. The result that the tissue is near equilibrium during the growth process suggests that the time scales over which the mechanical effects due to growth and in vivo or in vitro loading differ by several orders of magnitudes. Thus, to apply the CGM model with in vitro experiments, one may identify a time increment (e.g., one day) during which the mechanical effects of growth

20 are neglected. Then, the boundary-value problems obtained from existing analyses using classical mixture theory may be used to obtain time-averaged values of mechanical stimuli over this time increment. These time-averaged values may then be used in the growth laws to determine the growth tensors and an equilibrium growth boundary-value 
problem may be solved to obtain new values for tissue composition, stresses, and geometry. This approach would then proceed in an iterative fashion throughout the growth process. Such an approach is similar to that used in bone remodeling by Carter and colleagues (Beaupre et al. 1990; Carter and Wong 1988).

As a precursor to establishing the forms of the growth laws, in this paper the growth tensors were specified. The results suggest that it is important to quantify both the amount and orientation of proteoglycan and collagen mass deposition in order to predict the evolution of tissue composition and biomechanical function during growth. Experimental data that quantifies the changes in both the geometry of a growing tissue 10 explant as well as the constituent densities are necessary. The type of experiment that was conducted in (Buschmann et al. 1996) that quantified the spatial location of molecular deposition in the extracellular matrix could be used to fully characterize each growth tensor. Furthermore, the effect of various biochemical regulators on the growth law may be studied.

15 In this study, we used stress constitutive equations with non-physiological assumptions (e.g., infinitesimal strains, isotropic material symmetry, initially spherical pre-stresses, material homogeneity) in order to accomplish our objectives and to lay the foundation for future studies. In general, physiological growth problems will involve large growth deformations, which will usually cause large elastic deformations. The 20 solutions to these problems will employ a numerical solution technique where the incremental equilibrium boundary-value problem (e.g., see (Klisch et al. 2001)) is solved after obtaining a linear approximation to the growth law and stress constitutive equations. Consequently, more accurate constitutive models will include finite deformations, in 
addition to anisotropic material symmetry and material nonhomogeneity. Several experimental studies have quantified the nonlinear and nonhomogeneous mechanical properties of the cartilage solid matrix. A model for the solid matrix of cartilage has been proposed (Soltz and Ateshian 2000) that is capable of modeling the tension-compression 5 asymmetry that has been observed in developing cartilage, mature cartilage, and tissueengineered constructs. Many studies have quantified the depth-dependent mechanical properties of bovine and human articular cartilage. However, these nonlinear (Soltz and Ateshian 2000) and nonhomogeneous (Chen et al. 2001a; Chen et al. 2001b; Schinagl 1997) models have only been postulated for infinitesimal strains. In order to develop

10 constitutive equations that may be used accurately during a growth process, they must be validated for multiple experimental protocols and large strains. It is emphasized that accurate constitutive equations are necessary in order to validate the CGM model so that it can be used to predict in vitro and in vivo growth.

For example, the manner in which the collagen stress constitutive equation is

15 defined may be modified in several ways in order to better describe growth and remodeling. First, the use of a finite deformation constitutive equation can describe how the collagen material constants $\left(\lambda^{\mathrm{c}}, \mu^{\mathrm{c}}, \Gamma^{\mathrm{c}}\right)$ in (14) evolve due to the nonlinear effects of growth. In our recent paper (Klisch et al. 2003), we studied two non-physiologic, nonlinear collagen stress constitutive equations and used a "small-on-large" approach to

20 quantify how the collagen material constants for infinitesimal deformations superimposed on an equilibrium state evolve. A more accurate model may account for the presence of residual stress (i.e., a nonhomogeneous pre-stress); the general approach was developed in (Klisch et al. 2001). A first-order stress constitutive equation relative to a residually- 
stressed configuration was derived in (Johnson and Hoger 1993) and is similar to (14), although the pre-stress in (14) is allowed to be homogeneous and spherical due to the mixture approach whereas the residual stress in (Johnson and Hoger 1993) was necessarily nonhomogeneous. Second, the model assumes that the collagen matrix that is 5 deposited during growth has the same principal orientations as the existing collagen network, although the material constants are allowed to depend on a single remodeling parameter (e.g., crosslink density). Our preliminary results in applying the model with bovine cartilage explants (Klisch et al. 2003) suggest that there are other microstructural parameters that affect the collagen mechanical properties. Thus, it may be necessary to

10 incorporate additional microstructural variables into the CGM model. One promising approach for modeling the evolution of anisotropy has been recently published (Menzel 2005). ${ }^{9}$

The CGM model developed here assumes the existence of an extracellular proteoglycan-collagen matrix that is dense enough so that it can be modeled as a

15 continuum. The model seems best suited for studying the growth of either tissue explants or tissue engineered constructs that have formed an extracellular matrix. We have used the model to describe the growth of native tissue explants (Asanbaeva et al. 2004; Klisch et al. 2005) and plan on using it to describe the growth of tissue engineered constructs using the alginate recovery method (Masuda et al. 2003), in which constructs are formed 20 using chondrocytes that have an intact pericellular matrix after being cultured in alginate beads. Most cartilage tissue engineering experiments are conducted by seeding

\footnotetext{
${ }^{9}$ Anisotropy may also develop due to the nonlinear effects of growth; for example, anisotropic growth of an isotropic material will generally lead to a configuration for which the mechanical response relative to the new configuration is anisotropic.
} 
chondrocytes onto synthetic matrices. The CGM may be used to model those experiments by using the theory for an arbitrary number of growing constituents (Klisch et al. 2000; Klisch and Hoger 2003) to include an additional constituent representing the synthetic matrix, which may be allowed to "grow" to represent degradation of a biodegradable

5 scaffold (e.g., see (Wilson et al. 2002)). In this case, the analysis may begin with no proteoglycans or collagens present in the extracellular matrix, which then grow via conversion from the culture medium. However, preliminary studies may indicate that it is necessary to delay analysis with the CGM model until a sufficient amount of time in culture has passed so that an intact extracellular matrix exists.

10 Ultimately, a CGM model may be used to develop a better understanding of the key mechanisms of cartilage growth in the specific context of repairing damaged cartilage. With the development of more accurate stress constitutive equations and the experimental determination of the growth laws, the CGM model may serve as a paradigm for quantifying the in vitro growth of tissue engineered cartilage constructs and the in

15 vivo growth upon implantation for the repair of cartilage defects.

\section{ACKNOWLEDGMENTS}

Funding was received from NIH, NSF, and NASA.

\section{APPENDIX}

In this appendix, we outline a cartilage growth mixture (CGM) model for finite

20 deformations obtained from the general growth mixture theory presented in (Klisch et al. 2000; Klisch and Hoger 2003) with the simplifying assumptions presented in the Methods section. 
Kinematics. The deformation gradient tensors $\mathbf{F}^{\alpha}$ (superscript $\alpha=\mathrm{p}$ (proteoglycan), c (collagen), oth (others)) for the growing solid matrix constituents are decomposed as

$$
\mathbf{F}^{\alpha}=\mathbf{M}_{\mathrm{e}}^{\alpha} \mathbf{M}_{\mathrm{g}}^{\alpha} .
$$

The tensor $\mathbf{M}_{\mathrm{e}}^{\alpha} \mathbf{M}_{\mathrm{g}}^{\alpha}$ describes the deformation due to growth relative to a fixed reference

5 configuration, where the amount and orientation of mass deposition are described by $\mathbf{M}_{\mathrm{g}}^{\alpha}$. The tensor $\mathbf{M}_{\mathrm{e}}^{\alpha}$ is the elastic accommodation tensor that ensures continuity of the growing body, and may include a contribution arising from a superposed elastic deformation. The diffusive velocity $\mathbf{a}$ is defined as

$$
\mathbf{a}=\mathbf{v}^{\mathrm{w}}-\mathbf{v}^{\mathrm{s}}
$$

10 where $\mathbf{v}^{\mathrm{w}}$ is the fluid velocity and $\mathbf{v}^{\mathrm{s}}$ is the solid velocity. The constraint that the growing solid matrix constituents experience the same overall motion requires their displacement vectors $\left(\mathbf{u}^{\alpha}\right)$ and velocity vectors $\left(\mathbf{v}^{\alpha}\right)$ must equal the solid matrix displacement $\left(\mathbf{u}^{\mathrm{s}}\right)$ and velocity $\left(\mathbf{v}^{\mathrm{s}}\right)$ vectors:

$$
\mathbf{u}^{\mathrm{s}}=\mathbf{u}^{\mathrm{p}}=\mathbf{u}^{\mathrm{c}}=\mathbf{u}^{\text {oth }}, \quad \mathbf{v}^{\mathrm{s}}=\mathbf{v}^{\mathrm{p}}=\mathbf{v}^{\mathrm{c}}=\mathbf{v}^{\text {oth }} .
$$

15 Consequently, the deformation gradient tensors $\mathbf{F}^{\alpha}$ of the growing solid matrix constituents must equal the solid matrix deformation gradient tensor $\mathbf{F}^{\mathrm{s}}$ :

$$
\mathbf{F}^{\mathrm{s}}=\mathbf{F}^{\mathrm{p}}=\mathbf{F}^{\mathrm{c}}=\mathbf{F}^{\mathrm{oth}} \quad \Rightarrow \quad \mathbf{F}^{\mathrm{s}}=\mathbf{M}_{\mathrm{e}}^{\mathrm{p}} \mathbf{M}_{\mathrm{g}}^{\mathrm{p}}=\mathbf{M}_{\mathrm{e}}^{\mathrm{c}} \mathbf{M}_{\mathrm{g}}^{\mathrm{c}}=\mathbf{M}_{\mathrm{e}}^{\text {oth }} \mathbf{M}_{\mathrm{g}}^{\mathrm{oth}} .
$$

The constraint of intrinsic incompressibility states that the mixture is fully saturated with constant true densities:

$$
\phi^{\mathrm{p}}+\phi^{\mathrm{c}}+\phi^{\mathrm{oth}}+\phi^{\mathrm{w}}=1
$$


where $\phi^{\alpha}=\rho^{\alpha} / \rho^{\alpha \mathrm{T}}$ is the volume fraction, $\rho^{\alpha}$ is the apparent density (mass/tissue volume), $\rho^{\alpha \mathrm{T}}$ is the true density (mass/constituent volume), and superscript $\mathrm{w}=$ water.

Balance of mass. The standard balance of mass equations are generalized by introducing mass growth functions $\left(\mathrm{c}^{\alpha}\right)$ that quantify the rate of mass deposition per unit current mass

5 for the growing solid matrix constituents. Due to the constraint (A3), we obtain

$$
\dot{\rho}^{\alpha}+\rho^{\alpha} \operatorname{div} \mathbf{v}^{\mathrm{s}}=\rho^{\alpha} \mathrm{c}^{\alpha}, \quad \dot{\rho}^{\mathrm{w}}+\rho^{\mathrm{w}} \operatorname{div} \mathbf{v}^{\mathrm{w}}=0,
$$

where a superposed dot indicates the material time derivative following the appropriate constituent and $\operatorname{div}(\cdot)$ is the divergence operator. The balance of mass equation for each growing solid matrix constituent is decomposed into two equations by assuming that the

10 apparent density changes only because of the elastic part of the deformation. Thus, the balance of mass equations for the growing solid matrix constituents become

$$
\rho^{\alpha} \operatorname{det} \mathbf{M}_{\mathrm{e}}^{\alpha}=\rho_{\mathrm{R}}^{\alpha}
$$

where $\rho_{\mathrm{R}}^{\alpha}$ is the reference apparent density. Growth continuity equations are then derived from (A6) ${ }_{1}$ and (A7):

$$
\operatorname{det} \mathbf{M}_{\mathrm{g}}^{\alpha}=\exp \left(\int_{\tau=t_{0}}^{\mathrm{t}} \mathrm{c}^{\alpha} \mathrm{d} \tau\right)
$$

where $\operatorname{det}(\cdot)$ is the determinant operator. The balance of mass equation for the mixture requires

$$
\rho^{\mathrm{p}} c^{\mathrm{p}}+\rho^{\mathrm{c}} c^{\mathrm{c}}+\rho^{\text {oth }} c^{\text {oth }}=\rho^{\mathrm{s}} c^{\mathrm{s}}
$$

where $\mathrm{c}^{\mathrm{s}}$ is the mass growth function for the solid matrix. 


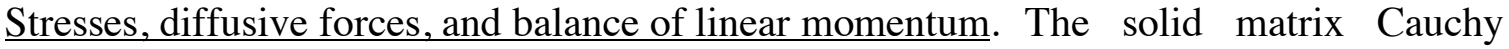
stress tensor $\mathbf{T}^{\mathrm{s}}$ and diffusive force $\pi^{\mathrm{s}}$ are assumed to be the sum of the partial solid matrix constituent stresses $\mathbf{T}^{\alpha}$ and diffusive forces $\pi^{\alpha}$, respectively:

$$
\mathbf{T}^{\mathrm{s}}=\mathbf{T}^{\mathrm{p}}+\mathbf{T}^{\mathrm{c}}+\mathbf{T}^{\mathrm{oth}}, \quad \pi^{\mathrm{s}}=\pi^{\mathrm{p}}+\pi^{\mathrm{c}}+\pi^{\text {oth }} .
$$

5 It was shown in (Klisch et al. 2000; Klisch and Hoger 2003) that the constraint (A4) produces constraint responses in $\mathbf{T}^{\alpha}$ and $\pi^{\alpha}$ which cancel upon addition when forming the solid matrix stress tensor and diffusive force vector. Consequently, the balance of linear momentum equations reduce to one for the solid and one for the fluid:

$$
\operatorname{div} \mathbf{T}^{\mathrm{s}}+\pi^{\mathrm{s}}=\rho^{\mathrm{s}} \dot{\mathbf{v}}^{\mathrm{s}}, \quad \operatorname{div} \mathbf{T}^{\mathrm{w}}+\pi^{\mathrm{w}}=\rho^{\mathrm{w}} \dot{\mathbf{v}}^{\mathrm{w}} .
$$

10 The balance of linear momentum for the mixture requires

$$
\pi=\pi^{\mathrm{s}}=-\pi^{\mathrm{w}},
$$

where $\pi$ is the diffusive force.

Growth laws. To obtain a complete theory, growth response functions that describe the time-rate of change of $\mathbf{M}_{\mathrm{g}}^{\alpha}$ for the growing solid matrix constituents are defined.

15 Mathematically, growth response functions of the general form are represented as

$$
\dot{\mathbf{M}}_{\mathrm{g}}^{\alpha}=\hat{\boldsymbol{G}}^{\alpha}\left(M^{\alpha}\right),
$$

where $\hat{\boldsymbol{G}}^{\alpha}$ is a function of mechanical stimuli $M^{\alpha}$ that drives the growth process for each growing solid matrix constituent.

Constitutive equations. Constitutive equations are required for the partial stresses as well

20 as the diffusive force. In (Klisch et al. 2000; Klisch and Hoger 2003), constitutive restrictions were derived that relate the constituent stresses to partial Helmholtz free energy functions that were allowed to depend on the elastic deformation gradient tensors 
and their gradients, fluid density and its gradient, diffusive velocity, and temperature. Here, we restrict those constitutive equations substantially as discussed in the Methods section. Generally, the assumed stress and diffusive force constitutive equations in the CGM model are

$$
\begin{aligned}
& \mathbf{T}^{\mathrm{p}}=-\phi^{\mathrm{p}} \mathrm{p} \mathbf{I}+\hat{\mathbf{T}}^{\mathrm{p}}\left(\mathbf{M}_{\mathrm{e}}^{\mathrm{p}}, \mathbf{M}_{\mathrm{e}}^{\mathrm{c}}, \rho^{\mathrm{w}}\right), \\
& \mathbf{T}^{\mathrm{c}}=-\phi^{\mathrm{c}} \mathrm{p} \mathbf{I}+\hat{\mathbf{T}}^{\mathrm{c}}\left(\mathbf{M}_{\mathrm{e}}^{\mathrm{c}}, \gamma\right), \\
& \mathbf{T}^{\mathrm{oth}}=-\phi^{\mathrm{oth}} \mathrm{p} \mathbf{I}, \\
& \mathbf{T}^{\mathrm{w}}=-\phi^{\mathrm{w}} \mathrm{p} \mathbf{I}, \\
& \pi=\frac{\operatorname{grad} \rho^{\mathrm{s}}}{\rho^{\mathrm{sT}}} \mathrm{p} \mathbf{I}+\hat{\pi}\left(\mathbf{F}^{\mathrm{s}}, \mathbf{a}\right),
\end{aligned}
$$

10 where $\mathbf{I}$ is the identity tensor, p is an arbitrary Lagrange multiplier (i.e., the fluid pore pressure) that arises due to the intrinsic incompressibility constraint, and $\gamma$ is a collagen remodeling parameter that may model a structural change in collagen network integrity (e.g., collagen crosslink density). 


\section{REFERENCES}

[1] Asanbaeva A, McGowan KB, Masuda K, Klisch SM, Thonar EJ-MA, Sah RL (2004) Mechanisms of cartilage growth: Alteration and function and composition in vitro by deposition of collagen and proteoglycan matrix components. Trans Orthop Res Soc 29: 554

[2] Bachrach NB, Mow VC, Guilak F (1998) Incompressibility of the solid matrix of articular cartilage under high hydrostatic pressures. J Biomech 31: 445-451

[3] Basser PJ, Schneiderman R, Bank RA, Wachtel E, Maroudas A (1998) Mechanical properties of the collagen network in human articular cartilage as measured by osmotic stress technique. Arch Biochem Biophys 351: 207-219

[4] Beaupre GS, Orr TE, Carter DR (1990) An approach for time-dependent bone modeling and remodeling - theoretical development. J Orthop Res 8: 651-661

[5] Buckwalter JA, Mankin HJ (1998) Articular cartilage: Degeneration and osteoarthritis, repair, regeneration, and transplantation. Instr Course Lect 47: 487-504 [6] Buschmann MD, Maurer AM, Berger E, Hunziker EB (1996) A method of quantitative autoradiography for the spatial localization of proteoglycan synthesis rates in cartilage. J Histochem Cytochem 44: 423-431

[7] Buschmann MD, Kim YJ, Wong M, Frank E, Hunziker EB, Grodzinsky AJ (1999) Stimulation of aggrecan synthesis in cartilage explants by cyclic loading is localized to regions of high interstitial fluid flow. Arch Biochem Biophys 366: 1-7

[8] Carter DR, Wong M (1988) Mechanical stresses and endochondral ossification in the chondroepiphysis. J Orthop Res 6: 148-154

[9] Chen AC, Bae WC, Schinagl RM, Sah RL (2001a) Depth- and strain-dependent mechanical and electromechanical properties of full-thickness bovine articular cartilage in confined compression. J Biomech 34: 1-12

[10] Chen SS, Falcovitz YH, Schneiderman R, Maroudas A, Sah RL (2001b) Depthdependent compressive properties of normal aged human femoral head articular cartilage. Osteoarthritis Cartilage 9: 561-569

[11] Chen SS, Sah RL (2001) Contribution of collagen network and fixed charge to the confined compression modulus of articular cartilage. Trans Orthop Res Soc 26: 426 [12] Davisson TH, Kunig S, Chen AC, Sah RL, Ratcliffe A (2002a) Static and dynamic compression modulate biosynthesis in tissue engineered cartilage. J Orthop Res 20: 842848

[13] Davisson TH, Sah RL, Ratcliffe AR (2002b) Perfusion increases cell content and matrix synthesis in chondrocyte three-dimensional cultures. Tissue Eng 8: 807-816 [14] Dunkelman NS, Zimber MP, LeBaron RG, Pavelec R, Kwan M, Purchio AF (1995) Cartilage production by rabbit articular chondrocytes on polyglycolic acid scaffolds in a closed bioreactor system. Biotechnol Bioeng 46: 299-305

[15] Epstein M, Maugin GA (2000) Thermomechanics of volumetric growth in uniform bodies. Int J Plast 16: 951-978

[16] Frank EH, Grodzinsky AJ (1987) Cartilage electromechanics-ii. A continuum model of cartilage electrokinetics and correlation with experiments. J Biomech 20: 629639 
[17] Garikipati K, Arruda EM, Grosh K, Narayanan H, Calve S (2004) A continuum treatment of growth in biological tissue: The coupling of mass transport and growth. $\mathrm{J}$ Mech Phys Sol 52: 1595-1625

[18] Green AE, Naghdi PM (1970) The flow of fluid through an elastic solid. Acta Mechanica 9: 329-340

[19] Guilak F, Ratcliffe A, Mow VC (1995) Chondrocyte deformation and local tissue strain in articular cartilage: A confocal microscopy study. J Orthop Res 13: 410-421 [20] Guilak F, Sah RL, Setton LA (1997) Physical regulation of cartilage metabolism. In: Mow VC, Hayes WC (ed) Basic orthopaedic biomechanics Raven Press, New York [21] Humphrey JD, Rajagopal KR (2002) A constrained mixture model for growth and remodeling in soft tissues. Math Model Meth Appl Sci 12: 407-430

[22] Johnson BE, Hoger A (1993) The dependence of the elasticity tensor on residual stress. J Elasticity 33: 145-165

[23] Kisiday JD, Jin M, DiMicco MA, Kurz B, Grodzinsky AJ (2004) Effects of dynamic compressive loading on chondrocyte biosynthesis in self-assembling peptide scaffolds. J Biomech 37: 595-604

[24] Klein TJ, Schumacher BL, Schmidt TA, Li KW, Voegtline MS, Masuda K, Thonar EJ-MA, Sah RL (2003) Tissue engineering of articular cartilage with stratification using chondrocyte subpopulations. Osteoarthritis Cartilage 11: 595-602

[25] Klisch SM, Lotz JC (2000) A special theory of biphasic mixtures and experimental results for human annulus fibrosus tested in confined compression. J Biomech Eng 122: 180-188

[26] Klisch SM, Sah RL, Hoger A (2000) A growth mixture theory for cartilage. ASME Mechanics in Biology BED-46: 229-242

[27] Klisch SM, Van Dyke T, Hoger A (2001) A theory of volumetric growth for compressible elastic materials. Math Mech Solids 6: 551-575

[28] Klisch SM, Chen SS, Sah RL, Hoger A (2003) A growth mixture theory for cartilage with applications to growth-related experiments on cartilage explants. J Biomech Eng 125: 169-179

[29] Klisch SM, Hoger A (2003) Volumetric growth of thermoelastic materials and mixtures. Math Mech Solids 8: 377-402

[30] Klisch SM, Asanbaeva A, Sah RL, Davol A (2005) Cartilage growth mixture model: Finite strain theory, constitutive equations, and boundary-value problem solutions Int Plast Symp

[31] Lai WM, Hou JS, Mow VC (1991) A triphasic theory for the swelling and deformation behaviors of articular cartilage. J Biomech Eng 113: 245-258

[32] Lubarda VA, Hoger A (2002) On the mechanics of solids with a growing mass. Int $\mathbf{J}$ Solids Struct 39: 4627-4664

[33] Maroudas A, Bullough P, Swanson SA, Freeman MA (1968) The permeability of articular cartilage. J Bone Joint Surg Br 50: 166-177

[34] Maroudas A, Venn M (1977) Chemical composition and swelling of normal and osteoarthrotic femoral head cartilage. Ii. Swelling. Ann Rheum Dis 36: 399-406

[35] Masuda K, Sah RL, Hejna MJ, Thonar EJ-MA (2003) A novel two-step method for the formation of tissue engineered cartilage: The alginate-recovered-chondrocyte (arc) method. J Orthop Res 21: 139-148 
[36] Mauck RL, Soltz MA, Wang CC, Wong DD, Chao PH, Valhmu WB, Hung CT, Ateshian GA (2000) Functional tissue engineering of articular cartilage through dynamic loading of chondrocyte-seeded agarose gels. J Biomech Eng 122: 252-260

[37] Menzel A (2005) Modelling of anisotropic growth in biological tissues: A new approach and computational aspects. Biomech Model Mechanobiol in press:

[38] Mills N (1966) Incompressible mixtures of newtonian fluids. Int J Eng Sci 4: 97-112 [39] Mow VC, Kuei SC, Lai WM, Armstrong CG (1980) Biphasic creep and stress relaxation of articular cartilage in compression: Theory and experiment. J Biomech Eng 102: $73-84$

[40] Mow VC, Ratcliffe A (1997) Structure and function of articular cartilage and meniscus. In: Mow VC, Hayes WC (ed) Basic orthopaedic biomechanics Raven Press, New York

[41] Pazzano D, Mercier KA, Moran JM, Fong SS, DiBiasio DD, Rulfs JX, Kohles SS, Bonassar LJ (2000) Comparison of chondrogensis in static and perfused bioreactor culture. Biotechnol Prog 16: 893-896

[42] Pottenger LA, Webb JE, Lyon NB (1985) Kinetics of extraction of proteoglycans from human cartilage. Arthritis Rheum 28: 323-330

[43] Quiligotti S (2002) On bulk growth mechanics of solid-fluid mixtures: Kinematics and invariance requirements. Theor Appl Mech 28-29: 277-288

[44] Rodriguez EK, Hoger A, McCulloch AD (1994) Stress-dependent finite growth in soft elastic tissues. J Biomech 27: 455-467

[45] Sah RL, Kim YJ, Doong JH, Grodzinsky AJ, Plaas AHK, Sandy JD (1989)

Biosynthetic response of cartilage explants to dynamic compression. J Orthop Res 7:

619-636

[46] Sah RL, Trippel SB, Grodzinsky AJ (1996) Differential effects of serum, igf-i, and fgf- 2 on the maintenance of cartilage physical properties during long-term culture. $\mathrm{J}$

Orthop Res 14: 44-52

[47] Sajdera SW, Hascall VC (1969) Proteinpolysaccharide complex from bovine nasal cartilage. A comparison of low and high shear extraction procedures. J Biol Chem 244: 77-87

[48] Schinagl RM, Gurskis D, Chen AC, Sah RL (1997) Depth-dependent confined compression modulus of full-thickness bovine articular cartilage. J Orthop Res 15: 499506

[49] Schreiber RE, Ilten-Kirby BM, Dunkelman NS, Symons KT, Rekettye LM, Willoughby J, Ratcliffe A (1999) Repair of osteochondral defects with allogeneic tissue engineered cartilage implants. 367S: 382-395

[50] Setton LA, Zhu W, Mow VC (1993) The biphasic poroviscoelastic behavior of articular cartilage: Role of the surface zone in governing the compressive behavior. $\mathbf{J}$ Biomech 26: 581-592

[51] Skalak R, Gasgupta G, Moss M, Otten E, Dullemeijer P, Vilmann H (1982)

Analytical description of growth. J Theor Biol 94: 555-577

[52] Skalak R, Zargaryan S, Jain RK, Netti PA, Hoger A (1996) Compatability and the genesis of residual stress by volumetric growth. J Math Biol 34: 889-914

[53] Skalak R, Farrow DA, Hoger A (1997) Kinematics of surface growth. J Math Biol 35: 869-907 
[54] Soltz MA, Ateshian GA (2000) A conewise linear elasticity mixture model for the analysis of tension-compression nonlinearity in articular cartilage. J Biomech Eng 122: 576-586

[55] Thibault M, Poole AR, Buschmann MD (2002) Cyclic compression of cartilage/bone explants in vitro leads to physical weakening, mechanical breakdown of collagen and release of matrix fragments. J Orthop Res 20: 1265-1273

[56] Venn MF, Maroudas A (1977) Chemical composition and swelling of normal and osteoarthritic femoral head cartilage. I. Chemical composition. Ann Rheum Dis 36: 121129

[57] Wang CC-B, Hung CT, Mow VC (2001) An analysis of the effects of depthdependent aggregate modulus on articular cartilage stress-relaxation behavior in compression. J Biomech 34: 75-84

[58] Williamson AK, Chen AC, Sah RL (2001) Compressive properties and functioncomposition relationships of developing bovine articular cartilage. J Orthop Res 19: $1113-1121$

[59] Williamson AK, Masuda K, Thonar EJ-MA, Sah RL (2003) Growth of immature articular cartilage in vitro: Correlated variation in tensile biomechanical and collagen network properties. Tissue Eng 9: 625-634

[60] Wilson CG, Bonassar LJ, Kohles SS (2002) Modeling the dynamic composition of engineered cartilage. Arch Biochem Biophys 408: 246-254

[61] Wong M, Ponticiello M, Kovanen V, Jurvelin JS (2000) Volumetric changes of articular cartilage during stress relaxation in unconfined compression. J Biomech 33: 1049-1054

[62] Woo SL-Y, Akeson WH, Jemmott GF (1976) Measurements of nonhomogeneous directional mechanical properties of articular cartilage in tension. J Biomech 9: 785-791 
Table 1: Input parameters for CGM model estimated from a typical bovine calf cartilage explant harvested from the patellofemoral groove.

\begin{tabular}{||l|c||}
\hline \hline PARAMETER & VALUE \\
\hline$\phi_{\mathrm{R}}^{\mathrm{w}}$ & 0.877 \\
\hline$\phi_{\mathrm{R}}^{\mathrm{p}}$ & 0.013 \\
\hline$\phi_{\mathrm{R}}^{\mathrm{c}}$ & 0.072 \\
\hline$\phi_{\mathrm{R}}^{\mathrm{o}}$ & 0.038 \\
\hline $\mathrm{T}_{\mathrm{R}}^{\mathrm{p}}(\mathrm{MPa})$ & -0.048 \\
\hline $\mathrm{T}_{\mathrm{R}}^{\mathrm{c}}(\mathrm{MPa})$ & 0.048 \\
\hline $\mathrm{H}_{\mathrm{A}}(\mathrm{Mpa})$ & 0.213 \\
\hline $\mathrm{k}\left(\mathrm{m}^{4} / \mathrm{N}-\mathrm{s}\right)$ & $3.07 \times 10^{-15}$ \\
\hline $\mathrm{H}_{\mathrm{A}}^{\mathrm{p}}(\mathrm{MPa})$ & 0.088 \\
\hline $\mathrm{H}_{\mathrm{A}}^{\mathrm{c}}(\mathrm{MPa})$ & 0.125 \\
\hline$\eta^{\mathrm{p}}(\mathrm{MPa})$ & 0.065 \\
\hline$\eta^{\mathrm{c}}(\mathrm{MPa})$ & 0.011 \\
\hline$\eta^{\mathrm{w}}(\mathrm{MPa})$ & 0.086 \\
\hline$\lambda^{\mathrm{c}}(\mathrm{MPa})$ & -0.061 \\
\hline$\mu^{\mathrm{c}}(\mathrm{MPa})$ & 0.093 \\
\hline \hline
\end{tabular}



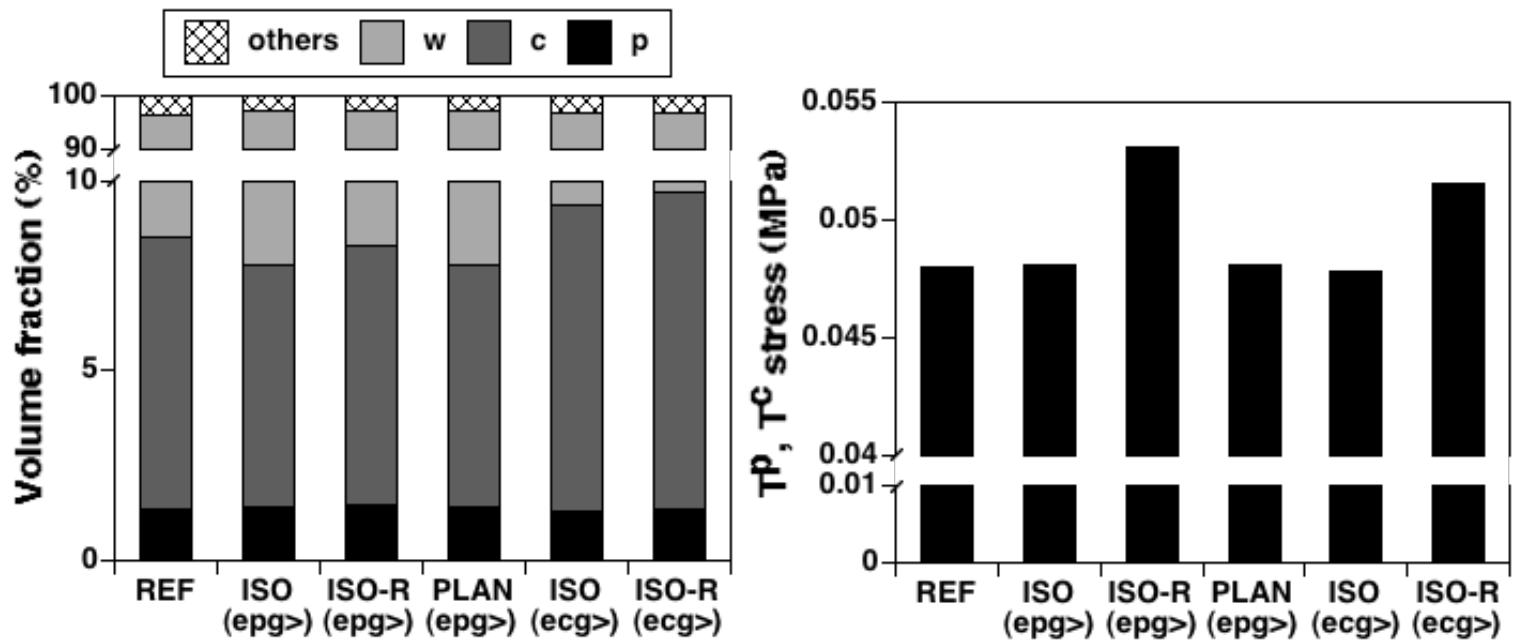

Figure 1: Volume fraction and stress results for homogeneous equilibrium growth boundary-value problems. The stresses were spherical tensors, $\mathrm{T}^{\mathrm{p}}$ was negative, and $\mathrm{T}^{\mathrm{c}}$ was positive. 

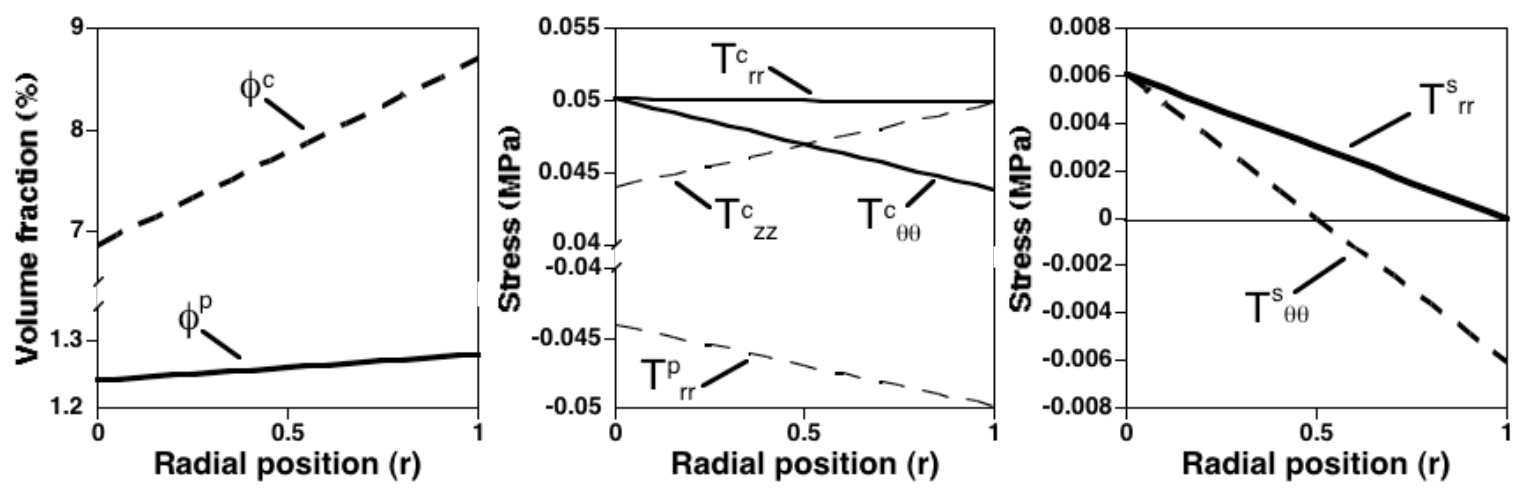

Figure 2: Volume fraction and stress results for the nonhomogeneous equilibrium growth boundary-value problem ( ISO - $\mathrm{NH}\left(\mathrm{e}_{\mathrm{g}}^{\mathrm{c}}>\right)$ ). The proteoglycan stress is a spherical tensor; i.e., $\mathrm{T}_{\mathrm{rr}}^{\mathrm{p}}=\mathrm{T}_{\theta \theta}^{\mathrm{p}}=\mathrm{T}_{\mathrm{zz}}^{\mathrm{p}}$. The solid matrix axial stress $\mathrm{T}_{\mathrm{zz}}^{\mathrm{s}}$ was zero everywhere. 


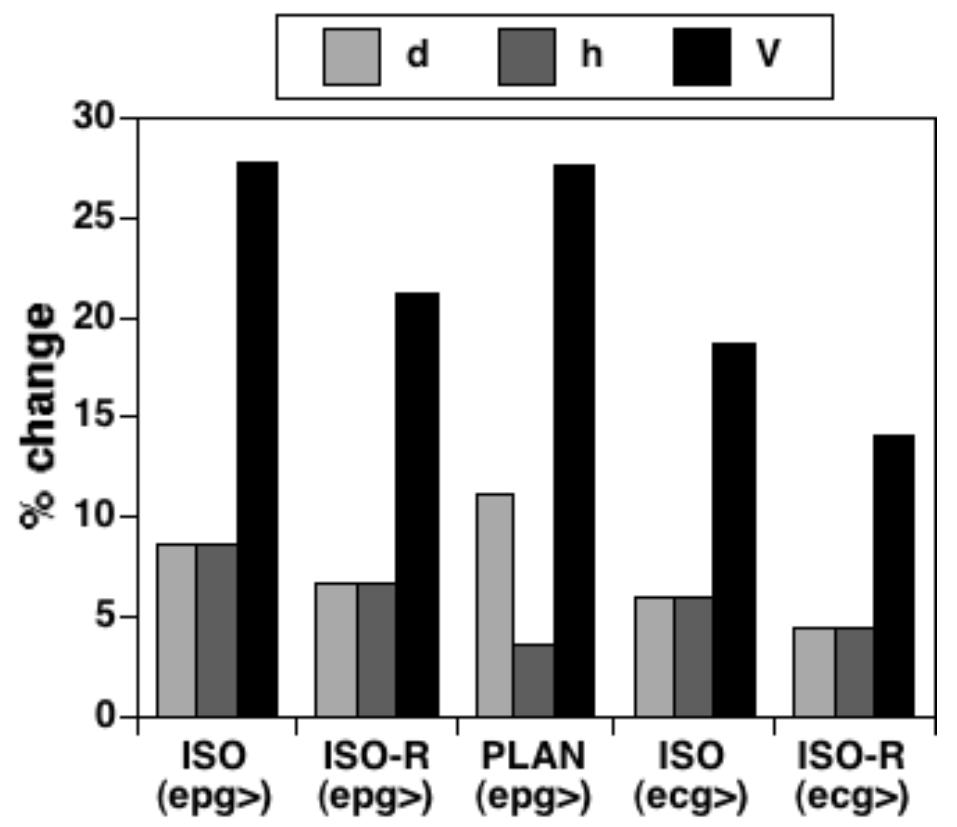

Figure 3: Geometry results: percent increase in diameter $(\mathrm{d} ; \mathrm{mm})$, height $(\mathrm{h} ; \mathrm{mm})$ and volume $\left(\mathrm{V} ; \mathrm{mm}^{3}\right)$ for equilibrium growth boundary-value problems. 

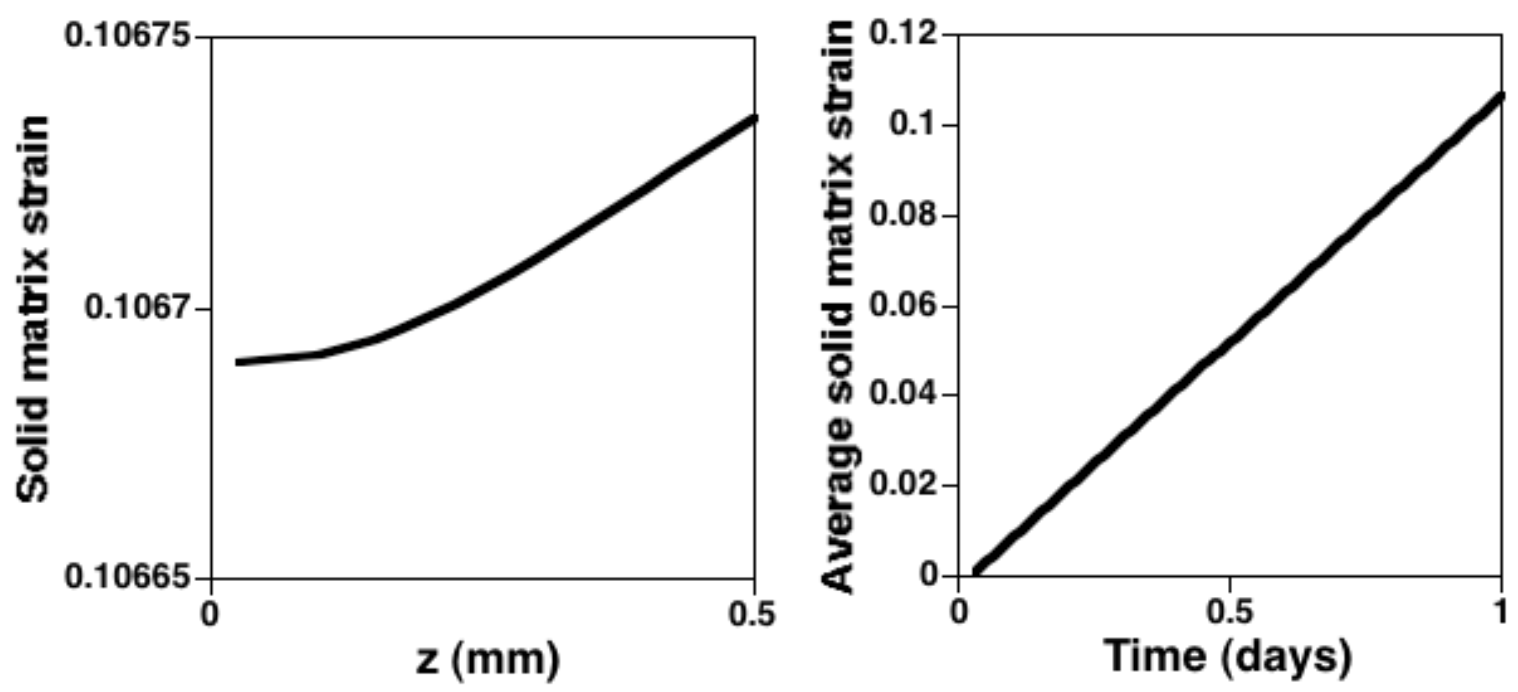

Figure 4: Solid matrix strain vs. axial coordinate $\mathrm{z}$ (at one day) and average solid matrix strain vs. time results for the non-equilibrium growth boundary value problem. 

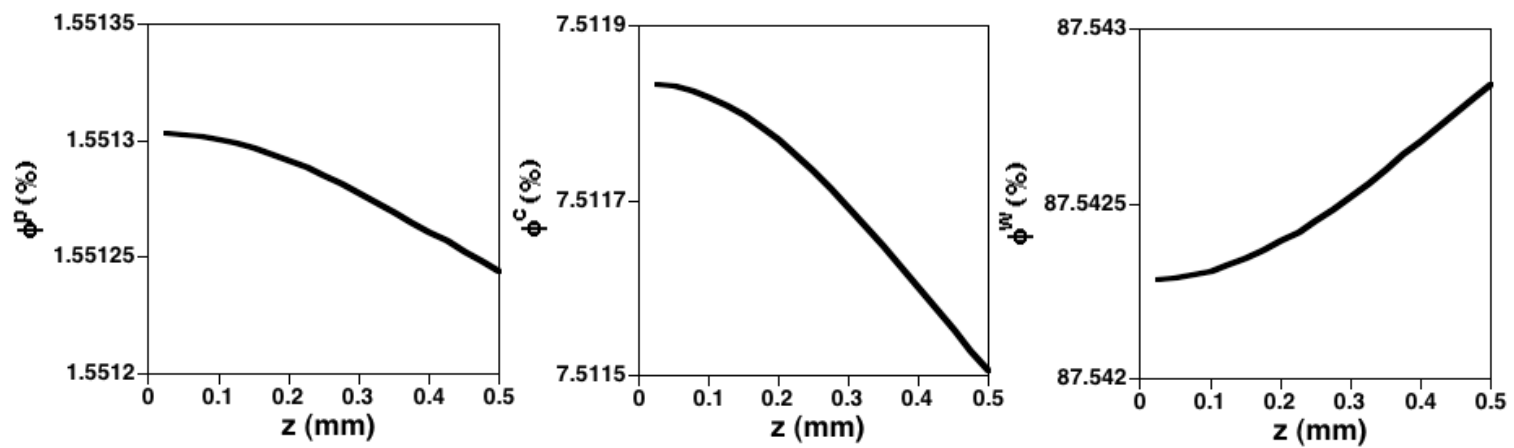

Figure 5: Volume fraction vs. axial coordinate $\mathrm{z}$ results (at one day) for the nonequilibrium growth boundary value problem. 

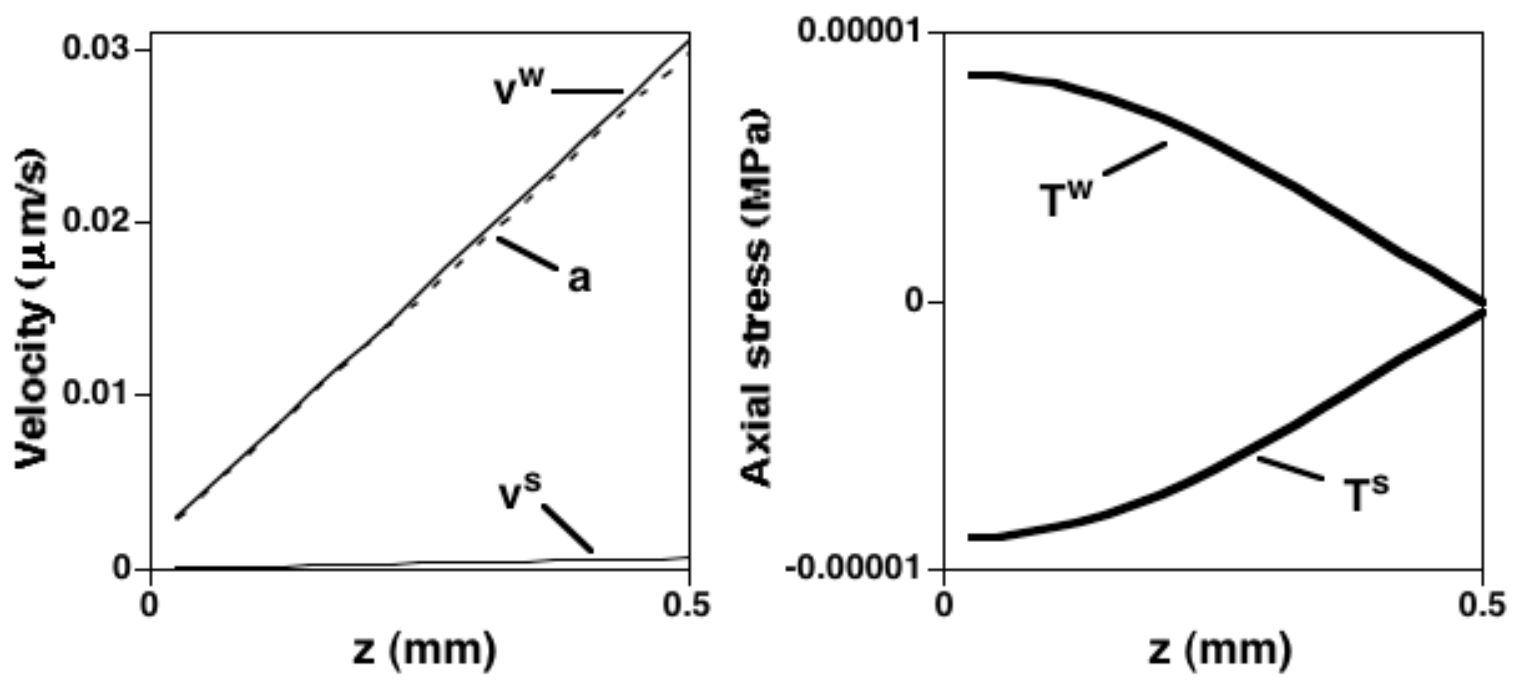

Figure 6: Velocities, solid matrix stress, and fluid stress vs. axial coordinate z results (at one day) for the non-equilibrium growth boundary value problem. 